This item was submitted to Loughborough's Research Repository by the author.

Items in Figshare are protected by copyright, with all rights reserved, unless otherwise indicated.

\title{
Common business cycles and volatilities in US states and MSAs: The role of economic uncertainty
}

PLEASE CITE THE PUBLISHED VERSION

https://doi.org/10.1016/j.jmacro.2018.06.009

\section{PUBLISHER}

(C) Elsevier

VERSION

AM (Accepted Manuscript)

\section{PUBLISHER STATEMENT}

This work is made available according to the conditions of the Creative Commons Attribution-NonCommercialNoDerivatives 4.0 International (CC BY-NC-ND 4.0) licence. Full details of this licence are available at: https://creativecommons.org/licenses/by-nc-nd/4.0/

\section{LICENCE}

CC BY-NC-ND 4.0

\section{REPOSITORY RECORD}

Gupta, Rangan, J. Ma, Marian Risse, and Mark E. Wohar. 2019. "Common Business Cycles and Volatilities in US States and Msas: The Role of Economic Uncertainty". figshare. https://hdl.handle.net/2134/35428. 


\section{Common Business Cycles and Volatilities in US States and MSAs: The Role of Economic Uncertainty\#}

\section{Introduction}

Following the recent global financial crisis, a burgeoning literature, both theoretical and empirical, has analysed the link between uncertainty and the macroeconomy. For instance, based on early works involving partial equilibrium models of Bernanke (1983) and, Dixit and Pindyck (1994), several researchers ${ }^{1}$ have recently developed dynamic stochastic general equilibrium models to capture the (negative) impact of uncertainty on macroeconomic variables. At the same time, large amount of empirical research ${ }^{2}$ have also been undertaken to validate the predictions of these theoretical models. ${ }^{3}$

Uncertainty is a latent variable, but, in order to quantify the impact of uncertainty on the macroeconomy, one requires ways to measure uncertainty. Besides the various alternative measures of uncertainty associated with financial markets (see Caldara et al., (2016), Giglio et al., (2016), and Dew-Becker et al., (2017) for detailed discussions of alternative measures), such as the implied-volatility indices (popularly called the VIX), realized volatility, idiosyncratic volatility of equity returns, corporate spread associated, a related strand in the literature has developed, primarily three broad approaches to quantify the effect of uncertainty on the economy: (1) The news-based approach proposed by Brogaard and Detzel (2015), Baker et al. (2016), and Larsen (2017). ${ }^{4}$ The main idea behind this approach is to perform searches of newspapers for terms related to economic and policy uncertainty (EPU) and to use the results of this search to construct measures of uncertainty; (2) Mumtaz and Zanetti (2013), Mumtaz and Surico (2013), Alessandri and Mumtaz (2014), Carriero et al. (2015, forthcoming), Jurado et al. (2015), Ludvigson et al. (2015), Mumtaz et al., (2016), Shin and Zhong (2016), Chuliá et al. (2017), Mumtaz and Theodoridis (2017a, b) and Creal and Wu (forthcoming) recover measures of uncertainty from estimates of various types of small and large-scale structural models related to macroeconomics and finance. Specifically speaking, the uncertainty measure is the average time-varying variance in the unpredictable component of a large set of real and financial time-series, i.e., it attempts to capture the average volatility in the shocks to the factors that summarize real and financial conditions, ${ }^{5}$ and; (3) Bali et al. (2015), Rossi and Sekhposyan

\footnotetext{
\# We would like to thank the Editor, Professor David VanHoose, and two anonymous referees for many helpful comments. However, any remaining errors are solely ours.

${ }^{1}$ See for example, Bloom (2009), Fernández-Villaverde et al., (2011, 2015), Gourio (2012), Leduc and Liu (2013), Johannsen (2013), Mumtaz and Zanetti (2013), Nakata (2013), Basu and Bundick (2014), Bloom et al. (2014), Christiano et al. (2014), and Carriero et al., (2015).

${ }^{2}$ See for example, Karnizova and Li (2014), Carriero et al. (2015), Jurado et al. (2015), Rossi and Sekhposyan (2015), Baker et al. (2016), Balcilar et al. (2016, 2017, forthcoming), Cheng et al. (2016), Jones and Enders (2016), Scotti (2016), Stockhammar and Österholm (2016, 2017), Berger et al., (2017), Caggiano et al., (2017), Choi (2017), Mumtaz and Theodoridis (2017), Carriero et al., (forthcoming), Creal and Wu (forthcoming), Gupta and Jooste (forthcoming), Gupta et al., (forthcoming), and Segnon et al. (forthcoming).

${ }^{3}$ For some earlier works and recent working papers, see also for example, Bachmann et al. (2013), Colombo (2013), Jones and Olson (2013, 2015), Caggiano et al. (2014a, b, 2016), Kang et al. (2014), Nodari (2014), Castelnuovo et al. (2015), Ludvigson et al. (2015), Mumtaz et al. (2016), and Rossi et al. (2016).

${ }^{4}$ Using a similar approach based on newspaper articles, Caldara and Iacoviello (2016), Manela and Moreira (2017), and Azzimonti (2018) developed measures of partisan conflict, geopolitical risks and news-based VIX (NVIX).

${ }^{5}$ These authors indicate that although in a general sense uncertainty is defined as the conditional volatility of an unforecastable disturbance, the empirical literature has usually relied on, which in turn can pick up fluctuations that are actually predictable and hence, can erroneously be attributable to uncertainty. Thus, it is important to distinguish between uncertainty in a series and its conditional volatility, i.e., properly measuring uncertainty would require one to remove the forecastable component of the considered series before computing the conditional volatility. In this sense, uncertainty in a series is not necessarily equivalent to the conditional volatility of the raw
} 
(2015, 2017), Rossi et al. (2016), and Scotti (2016) construct measures of uncertainty based on dispersion of professional forecaster disagreement.

Against this backdrop, the objective of this paper is to analyze, for the first time, the role of uncertainty in explaining common business cycles and volatilities in the 48 contiguous US states and 51 largest metropolitan statistical areas (MSAs) separately, over the quarterly period of 1948:Q1 to 2014:Q4, and the monthly period of 1990:M1 to 2015:M12, respectively. For our purpose to capture potential time-varying co-movement among the output measures of US states and MSAs, we first estimate the dynamic factor model of Del Negro and Otrok (2008), which allows for time-varying loadings and stochastic volatility (DFM-TV-SV). In the second step, we use a quantile-on-quantile (QQ) predictive regression model of Sim and Zhou (2015) to capture the effect of uncertainty on the common factor and stochastic volatility derived from the DFM-TV-SV for the states and MSAs. The advantage of a quantile regression approach over a conditional mean-based model is that the former can study the entire conditional distribution of the dependent variable, i.e., it is inherently a time-varying parameter approach capturing various phases (low [lower quantiles], normal [median], high [higher quantiles]) of the common factor and stochastic volatility. The QQ regression goes even a step further because it renders it possible to analyze the response of the entire conditional distribution of common factors and stochastic volatility to various degrees of uncertainty as well, as captured by its quantiles. As far as the metric of uncertainty is concerned, we use the news-based measure (economic policy uncertainty index; EPU) of Baker et al., (2016), primarily due to two reasons: (1) The measure does not require any complicated estimation of a large-scale model to generate it in the first place, and hence, is not model-specific, and; (2) While, other measures of uncertainty, like those developed by Jurado et al. (2015), and Rossi and Sekhposyan (2015), are also available publicly like the EPU, their coverage only starts from early or late 1960s. The EPU data goes as far back as 1900, and thus allows us to analyze the output data of the US states which begins in 1948.

Our paper based on the QQ model applied to the common factor of output growth and stochastic volatility derived from the DFM-TV-SV model, extends the above-discussed empirical literature on uncertainty and national macroeconomic effects (in general) to regional-levels involving the US states and MSAs. In addition, unlike the literature, we also analyze the impact of uncertainty on volatility of output, i.e., we look at higher-order effects. The only study that is somewhat related to our paper is the work of Mumtaz et al., (2016), wherein the authors use a FAVAR model with stochastic volatility to estimate the impact of uncertainty shocks on real income growth in US states. The results suggested that there is a large degree of heterogeneity in magnitude and persistence of the response to uncertainty shocks across states, with the magnitude of the decline in income being largest in states with a large share of manufacturing and construction industries, a larger share of small firms, a high fiscal deficit, a less rigid labor market and a more volatile housing market. But, in contrast, a higher share of mining industries and larger inter-governmental fiscal transfers is found to ameliorate the impact of uncertainty. Our paper is different from that of Mumtaz et al., (2016), in the sense that it makes a contribution to the understanding of the role played by uncertainty in explaining common business cycles and volatilities of not only the US states, but also largest MSAs over the entirety of their respective conditional distributions, following a change in uncertainty conditional on its current state. The QQ approach allows us to study the possible asymmetric impact of

series. In addition, Jurado et al., (2015) indicate that ideally macroeconomic uncertainty is defined as the common variation in uncertainty across many series rather than any single series, as suggested by the uncertainty-based business cycle theories. Given this, uncertainty is defined as the conditional volatility of the purely unforecastable component of the future value of multiple series. 
uncertainty on common growth and volatilities of the states and MSAs, given the current position of both the dependent variable and the predictor. Note that, MSA indices, compared to the state-level measure of economic activity, allow for an even more disaggregated geographical comparison of business cycles, thus permitting researchers to identify significant differences in economic activity that are masked by existing state indices (Arias et al., 2016). Given this, MSA indices provide a rich source of variation in economic activity that can be exploited to analyze important economic relations with greater precision. Understandably, the role played by uncertainty in explaining common business cycles of the MSAs are also clearly valuable to local governments for setting policy, with the behavior of these indices providing a more complete picture of differences in local economic activity when deciding on appropriate policies at the state and national levels.

Note that our paper also adds to the literature on regional (restricted to primarily state-level) business cycle synchronization of the US economy (see for example, Carlino and DeFina (2004), Crone (2005), Partridge and Rickman (2005), Owyang et al., (2005, 2008, 2009); Artis et al., (2011); Aguiar-Conraria et al., (2017)) - an important issue for policy makers in devising appropriate economic policies. These studies tend to suggest that state-level business cycles are highly synchronized (Aguiar-Conraria et al., 2017), with the common factor explaining large proportion of the total variability in state-level business cycles (Owyang et al., 2009). ${ }^{6}$ Understandably then, we do not only analyze the role of this common factor for both US states and MSAs, but more importantly, we evaluate the importance of uncertainty in explaining the movement of this common factor as an explanatory variable for business cycle synchronization, besides already emphasized covariates like industry mix, agglomeration, and neighbor effects (Owyang et al., 2009; Aguiar-Conraria et al., 2017), and monetary policy (Owyang and Wall, 2009) respectively. ${ }^{7}$ From a policymaker's perspective, if the common national factors of output and volatility actually drive regional business cycles and its fluctuations, with uncertainty in turn affecting these factors, then national-level policies are likely to ameliorate the negative influence of uncertainty for the US states and MSAs. Naturally, our paper has important policy implications. The remainder of the paper is organized as follows: Section 2 presents the data, while Section 3 lays out the basics of the DFM-TV-SV and QQ models. Section 4 discusses the results and Section 5 concludes.

\section{Data}

The DFM-TV-SV model is based on measures of economic activity for the 48 states (barring Alaska and Hawaii), and 51 largest MSAs as listed in Table A1 of the Appendix. For the states, we use the growth rates of quarterly real personal income in the DFM-TV-SV model, as the model requires stationary data. We deflate the seasonally adjusted nominal state personal income by the seasonally adjusted consumer price index (CPI) of the overall US economy to obtain the real counterpart of the variable, given that state-level CPI is not available at quarterly frequency for the period under consideration. While the personal income data comes from the regional database of the Bureau of Economic Analysis (US Department of Commerce), the CPI data (with a base year of 1982-1984) is derived from the FRED database of Federal Reserve

\footnotetext{
${ }^{6}$ Unlike our work, Owyang et al., (2009) estimated three factors using a standard fixed-coefficient DFM for the 48 contiguous states based on the growth rates of real personal income and payroll employment, and the growth rates of the M1 and M2 money stocks, S\&P 500 stock price index, and personal consumption expenditures (PCE) deflator; and first differences of the federal funds rate, 3-month Treasury bill yield, 10-year Treasury bond yield, and Moody's Seasoned Baa Corporate Bond yield. The authors then identified the first factor as the business cycle component in the data comprising of 106 state and national (financial) variables.

${ }^{7}$ In this regard also note that the role of national housing market permit values have been shown to be driving MSA-level employment in Ghent and Owyang (2010).
} 
Bank of St. Louis. For the MSAs, we use the monthly economic activity indices as developed by Arias et al., (2016) and available for download from the FRED database. These authors derived each of these indices from a DFM based on twelve underlying variables capturing various aspects of metro area economic activity. Seven (five) of the variables are monthly (quarterly). The variables include seven labor-market measures (average weekly hours worked, unemployment rate, private sector goods-producing employment, private sector servicesproducing employment, government sector employment, real average hourly earnings, real average quarterly wages), building permits, real personal income per capita, and three financial metrics (return on average assets, net interest margin, loan loss reserve ratio). The new metro indices developed by Aria et al., (2016) are based on a much broader set of variables than the few existing metro indices (as well as the state indices reported by the Federal Reserve Bank of Philadelphia, which are basically based on four labor-market variables). Arias et al., (2016) estimate the DFM by using a maximum-likelihood approach that allows for arbitrary patterns of missing data to accommodate mixed-frequency and differences in publication lags. These indices are stationary by design and hence, we apply the DFM-TV-SV directly on them without any further transformations.

The EPU indices used in this paper are derived from the work of Baker at al., (2016). To match the longer span of the state-level quarterly data on personal income, we use the historical version of the index, which dates as far back as $1900 .{ }^{8}$ The data is available for download from: http://www.policyuncertainty.com/us_historical.html. Since the state-level data on real personal income is quarterly, the monthly EPU index is converted into its quarterly frequency by taking averages over three-months comprising a quarter. With the real personal income starting in 1947 and the historical EPU ending in 2014, the state-level analysis covers the period of 1947:Q1-2014:Q4. We take natural logarithm of the EPU index (LEPU), with volatility being in its natural logarithmic form as well.

Given that the MSA economic activity indices start in 1990, the corresponding measure of uncertainty used is the benchmark EPU index developed by Baker et al., (2016), which in turn, starts in 1985. The data can be downloaded from: http://www.policyuncertainty.com/us_monthly.html. In this case, to measure policy-related economic uncertainty, Baker et al., (2016) construct the index from three types of underlying component: newspaper coverage of policy-related economic uncertainty; the number of federal tax code provisions set to expire in future years, and disagreement among economic forecasters. ${ }^{9}$ For the MSAs, our analysis covers the period of 1990:M1 to 2015:M12, with the

\footnotetext{
${ }^{8}$ Baker et al., (2016) use two overlapping sets of newspapers, with the first spanning the period of 1900-1985, and comprising of the Wall Street Journal, the New York Times, the Washington Post, the Chicago Tribune, the LA Times, and the Boston Globe. From 1985 until 2014, the authors use USA Today, the Miami Herald, the Dallas Morning Tribune, and the San Francisco Chronicle, along with the previously mentioned newspapers. To construct the index, Baker et al., (2016) perform month-by-month searches of each paper, for terms in all three categories pertaining to uncertainty, the economy and policy. In particular, the search is conducted for articles containing the term 'uncertainty' or 'uncertain', the terms 'economic', 'economy', 'business', 'commerce', 'industry', and 'industrial' as well as one or more of the following terms: 'congress', 'legislation', 'white house', 'regulation', 'federal reserve', 'deficit', 'tariff', or 'war'.

${ }^{9}$ The first component is based on the search results for terms related to economic and policy uncertainty from 10 large newspapers as mentioned previously in above footnote. In this case, Baker et al., (2016) search for articles containing the term 'uncertainty' or 'uncertain', the terms 'economic' or 'economy' and one or more of the following terms: 'congress', 'legislation', 'white house', 'regulation', 'federal reserve', or 'deficit'. The second component of the index uses reports of the Congressional Budget Office (CBO), which compiles lists of temporary federal tax code provisions. Temporary tax measures are a source of uncertainty for businesses and households, since Congress often extends them at the last minute; in the process, undermining stability in and certainty about the tax code. The third component draws on the Federal Reserve Bank of Philadelphia's Survey of Professional Forecasters.
} 
start and end dates being purely driven by the availability of the economic activity indices at the time of writing this paper. As in the case of the states, the EPU index is converted into its natural logarithmic form (LEPU).

Specifically, Baker et al., (2016) utilize the individual-level quarterly forecasts one year ahead for CPI, purchase of goods and services by state and local governments, and the same by the federal government. The overall EPU index is then constructed by first normalizing each component by its own standard deviation prior to January 2012, and then computing the weighted (1/2 on the first component and 1/6 each on the second and third components) average value of the components. 


\section{Econometric Frameworks}

\subsection{Dynamic Factor Model with Time-Varying Loadings and Stochastic Volatility (DFM-TV-SV):}

To capture potential time-varying co-movement among multiple series, we estimate the extended dynamic factor model with time-varying loadings and stochastic volatility (or DFMTV-SV) á la Del Negro and Otrok (2008). In the DFM-TV-SV framework, the growth rate in each state or the economic activity index in each MSA is decomposed into two components: national (common) factor and the regional (idiosyncratic) factor:

$y_{i, t}=\lambda_{i, t} \cdot f_{t}+e_{i, t}$.

Here $y_{i, t}$ is the growth rate (economic activity index) in state (MSA) $i(i=1,2, \ldots, n$, where $n$ is the total number of regions); $f_{t}$ is the national (common) factor that affects all regions. The loading parameter for the common factor $f_{t}$ is $\lambda_{i, t}$ for region $i$ at time $t$. Finally, $e_{i, t}$ is the regional (idiosyncratic) factor. The common and idiosyncratic factors are assumed to be orthogonal for the identification purpose.

This factor model is dynamic in the sense that all factors follow simple time series dynamics. Specifically, the common factor follows a stationary $\mathrm{AR}(p)$ process with time-varying stochastic volatility:

$$
f_{t}=\phi_{1}^{f} f_{t-1}+\phi_{2}^{f} f_{t-2}+\ldots+\phi_{p}^{f} f_{t-p}+\sqrt{\exp \left(h_{t}^{f}\right)} \cdot \varepsilon_{t}^{f}
$$

where $\varepsilon_{t}^{f} \sim$ i.i.d.N $\left(0, \sigma_{f}^{2}\right)$. The time varying stochastic volatility is modeled as a random walk for the sake of parsimony:

$h_{t}^{f}=h_{t-1}^{f}+\sigma_{f}^{h} \cdot v_{t}^{f}, v_{t}^{f} \sim$ i.i.d.N $(0,1)$,

where, $\sigma_{f}^{h}$ is the so-called volatility of the volatility and measures the size of time variations of the stochastic volatility.

Similarly, each idiosyncratic factor follows a stationary $\operatorname{AR}(q)$ process:

$e_{i, t}=\phi_{i, 1} e_{i, t-1}+\phi_{i, 2} e_{i, t-2}+\ldots+\phi_{i, q} e_{i, t-q}+\sqrt{\exp \left(h_{i, t}\right)} \cdot \varepsilon_{i, t}$,

where $\varepsilon_{i, t} \sim$ i.i.d.N $\left(0, \sigma_{i}^{2}\right)$. The stochastic volatility is again modeled as a random walk:

$h_{i, t}=h_{i, t-1}+\sigma_{i}^{h} \cdot v_{i, t}, v_{i, t} \sim$ i.i.d.N $(0,1)$,

where, $\sigma_{i}^{h}$ is the volatility of the volatility for the idiosyncratic factor. The volatility shocks of all factors are assumed to be orthogonal to each other as it is standard in this literature.

To permit more general time-varying co-movement among multiple series, the loading parameters in the model are allowed to vary over time and are modeled as random walk processes to keep the model parsimonious: 


$$
\lambda_{i, t}=\lambda_{i, t-1}+\eta_{i, t}, \eta_{i, t} \sim \text { i.i.d. } N\left(0, \sigma_{\eta, i}^{2}\right)
$$

We assume that the shocks to loading parameters are independent across series $i$. This assumption implies that the increasing or decreasing contribution of the common factor that are common to all series will be solely captured by the increasing or decreasing volatility of the common factor.

Once the model is estimated and conditional on knowing the time varying loading parameters at each point in time, the variance decomposition is given by:

$\operatorname{Var}\left(y_{i, t}\right)=\lambda_{i, t}^{2} \cdot \operatorname{Var}\left(f_{t}\right)+\operatorname{Var}\left(e_{i, t}\right)$.

To separately identify the loading parameters and the variance of the common factor, we follow the literature and normalize the common factor shock variance $\sigma_{f}^{2}=1$. Similar normalization applies to the time varying part of the factor volatility. Specifically, we set the initial values of the time-varying volatility $h$ 's in eq. (3) and (5) all to zero at the beginning, i.e., $h_{0}^{f}=h_{i, 0}=0$ for $i=1,2, \ldots, n$. Finally, to reduce the number of parameters to be estimated, we first demean all growth rate data before estimating the model.

The above DFM-TV-SV model is estimated by the Bayesian Markov Chain Monte Carlo (MCMC) method due to its large dimension and the resulting complex log likelihood function. Our estimation strategy employs the Gibbs-sampling algorithm that builds upon Kim et al., (1998), Kim and Nelson (1999), Primiceri (2005), Koop and Korobilis (2010), Del Negro and Otrok (2008), and Del Negro and Primiceri (2015). Specifically, we take draws from the known posterior conditional density sequentially for each block of the model. Most blocks involve standard sampling algorithms as outlined in Kim and Nelson (1999), except for the part of the time-varying stochastic volatility that results in a non-Gaussian shock in the measurement equation of the relevant state-space model, for which the usual Kalman filter no longer applies. To deal with this issue, we employ the approach as proposed by Kim, et al., (1998) that uses a mixture of normal densities to approximate the resulting non-Gaussian density function in order to make draws of the stochastic volatility. Cogley and Sargent (2005) take a different approach that utilizes a Metropolis-Hasting algorithm to make draws of the stochastic volatility. The approach in Kim et al., (1998) can be embedded in the Gibbs-sampling algorithm and has been widely applied in the literature to make draws of the stochastic volatility. Stock and Watson (2007) and Primiceri (2005) are notable examples that show this approach has worked fairly well. After the MCMC algorithm converges, the joint density of parameters and states can be numerically integrated to yield marginal distributions of parameters and states of interest. For further details on the estimation steps, readers are referred to the appendices of Bhatt, et al., (2017).

With respect to the model parameters, we set $p=q=2$ for the common and all idiosyncratic factors to keep the model parsimonious and, at the same time, allow for sufficient time series dynamics in terms of the factors. Our results are based on the 8000 Monte Carlo simulation draws after discarding 2000 initial burn-in draws. 


\subsection{Quantile-on-Quantile (QQ) Predictive Regression}

In order to study the predictive ability of the EPU for the common business cycle movements and stochastic volatilities of the US states and MSAs, we rely on a quantile-on-quantile (QQ) predictive regression model. Unlike a standard quantile regression which estimates the heterogeneous response of the common factor (of business cycle or volatility) to EPU at various points of the conditional distribution of the former, it overlooks the possibility that the change in EPU conditional on its current state could have variable influence on the common factor.

While there is also the triangular system of the equations-based approach of Ma and Koenker (2006) for estimating QQ models, we use the single equation regression method of Sim and Zhou (2015) given that it can be easily estimated.

Let $\theta$ denote the quantile of the common factor ( $C F)$ of economic activity ("Output") and logarithm of stochastic volatility ("LSV") under consideration. We first postulate a model for the $\theta$-quantile of $C F$ as a function of the first lag of EPU ("lagged LEPU”). We have:

$$
C F_{t}=\beta^{\theta} E P U_{t-1}+\varepsilon_{t}^{\theta},
$$

where $\varepsilon_{t}^{\theta}$ is an error term that has a zero $\theta$-quantile.

We allow the relationship function $\beta^{\theta}$ ( $E P U_{t-1}$ ) to be unknown, since we do not have a prior on how the $C F$ and $E P U$ changes are interlinked. To examine the linkage between the $\theta$-quantile of $C F$ and $\tau$-quantile of $E P U$, denoted by $E P U^{\tau}$, we linearize the function $\beta^{\theta}\left(E P U_{t-1}\right)$ by taking a first-order Taylor expansion of $\beta^{\theta}\left(\right.$.) around $E P U^{\tau}$, which yields:

$$
\beta^{\theta}\left(E P U_{t-1}\right) \approx \beta^{\theta}\left(E P U^{\tau}\right)+\beta^{\theta^{\prime}}\left(E P U^{\tau}\right)\left(E P U_{t-1}-E P U^{\tau}\right)
$$

Based on Sim and Zhou's (2015) study, we can redefine $\beta^{\theta}\left(E P U^{\tau}\right)$ and $\beta^{\theta^{\prime}}\left(E P U^{\tau}\right)$, respectively, as $\beta_{0}(\theta, \tau)$ and $\beta_{1}(\theta, \tau)$. Then, equation (9) can be re-written as follows:

$$
\beta^{\theta}\left(E P U_{t-1}\right) \approx \beta_{0}(\theta, \tau)+\beta_{1}(\theta, \tau)\left(E P U_{t-1}-E P U^{\tau}\right)
$$

We substitute equation (10) into equation (8) to obtain:

$$
C F_{t}=\beta_{0}(\theta, \tau)+\beta_{1}(\theta, \tau)\left(E P U_{t-1}-E P U^{\tau}\right)+\varepsilon_{t}^{\theta} .
$$

Unlike a standard conditional quantile function, the expression

$$
\beta_{0}(\theta, \tau)+\beta_{1}(\theta, \tau)\left(E P U_{t-1}-E P U^{\tau}\right)
$$

captures the relationship between the $\theta$-quantile of the $C F$ and $\tau$-quantile of lagged $E P U$, given that $\beta_{0}$ and $\beta_{1}$ are doubly indexed in $\theta$ and $\tau$.That is, this expression can capture the overall dependence structure between the $C F$ and lagged EPU through the dependence between their respective distributions.

To estimate (11), we solve for: 


$$
\min _{\beta_{0} \beta_{1}} \sum_{i=1}^{n} \rho_{\theta}\left[C F_{t}-\beta_{0}-\beta_{1}\left(E P U_{t-1}-E P U^{\tau}\right)\right] K\left(\frac{F_{n}\left(E P U_{t-1}\right)-\tau}{h}\right)
$$

to obtain the estimates $\hat{\beta}_{0}(\theta, \tau)$ and $\hat{\beta}_{1}(\theta, \tau)$, where the function $\rho_{\theta}$ is the tilted absolute value function that provides the $\theta$-conditional quantile of $C F_{t}$ as the solution. Because we are interested in the effect exerted locally by the $\tau$-quantile of lagged EPU, we employ a Gaussian kernel $K($.$) to weight the observations in the neighbourhood of E P U^{\tau}$, based on bandwidth $h$ (=0.05, following Sim and Zhou (2015)). The weights are inversely related to the distance of $E P U_{t-1}$ from $E P U^{\tau}$, or more conveniently, the distance of the empirical distribution function

$F_{n}\left(E P U_{t-1}\right)=\frac{1}{n} \sum_{k=1}^{n} I\left(E P U_{k}<E P U_{t-1}\right)$

from $\tau$, where $\tau$ is the value of the distribution function that corresponds with $E P U^{\tau}$.

\section{Empirical Results}

Figures 1 and 5 plot the extracted national factors using the MSAs economic activity indices and state level real personal income data, respectively. ${ }^{10}$ The point estimate is based on the median of the MCMC draws and the dotted lines are the $95^{\text {th }}$ and $5^{\text {th }}$ percentiles as a way to gauge estimation accuracy. The much shorter sample in Figure 1 makes it easier to visualize the sharp economic downturn during the recent "Great Recession" that plagued all the MSAs. Although the national factor is much more volatile in Figure 5, it still shows the economic downturn during the "Great Recession" for the states as well.

Figures 2 and 6 plot the variance contributions of the national factors using the MSA's economic activity indices and state-level real personal income data, respectively. These variance contributions vary substantially over time justifying the necessity of estimating the DFM-TV-SV, which permits time-varying contributions. To better summarize the overall importance of the national factor to the regional economic activities over time, we compute the percentage contributions of the national factor to the state level real personal income in Table A2, and the corresponding quantities for the economic activity in 51 MSAs in Table A3. For the real personal income data that has a much longer sample span, the contributions of the national factor is over $50 \%$ across all states during the full sample period. This highlights the strong co-movement of the economic activities across different regions overall and the importance of the national factor in explaining regional economic fluctuations. However, there is also a large amount of heterogeneity across different states. For example, states such as North Dakota and South Dakota appear to have the least amount of exposure to the national factor, while states such as Wisconsin and Ohio are more influenced by the national factor overall. Turning to the economic activity in 51 MSAs for a much shorter time span, the role of the national factor seems to become smaller. But again, there is a lot of heterogeneity. Metropolitan areas such as Philadelphia and NY City have more than 70\% contributions of the national factor overall. Interestingly, for both datasets, right before the recent "Great Recession", the contributions of the national factor all appear to have increased markedly, followed by a gradual decline. Both tables show the average percentage contributions of the national factor before and after 2007Q4, the start of the "Great Recession" as defined by the NBER. This highlights the severity of this recent recession that affects all states and regions across the board. Since the

\footnotetext{
${ }^{10}$ The estimation of the most general model that permits time-varying loading parameters reveal a great deal of time variations in the same for both the MSA- and state-level datasets. Plots that contain estimates of the timevarying loading parameters along with their confidence intervals highlighting this time-variation is available upon request from the authors.
} 
contributions of the national factor to regional activities vary over time and across regions, these time-varying contributions help to understand the varying effects of the economic uncertainty on different regional activities over time through its impact on the common national factor.

Figures 3 and 7 present the time varying stochastic volatility of the national factors using both datasets corresponding to the MSAs and the states. Notably, the stochastic volatility increased during the recent "Great Recession". The increase of the stochastic volatility of the common factor tends to increase the contributions of the national factor, ceteris paribus. This helps to understand the impact the economic uncertainty could potentially have on the co-movement among regional economic activities through its effect on the time-varying stochastic volatility.

The DFM-TV-SV model can conveniently document the potentially time-varying comovement among multiple series, and therefore provide a straightforward way to summarize this useful statistical feature of the data. To this end, we compute and plot the implied average cross-correlations in the datasets for of all MSAs and states in Figures 4 and 8, respectively. To produce these time-varying average cross-correlations, we first compute all pairwise correlations implied by the estimated factor model at each point in time and then take the crosssectional average. Consistent with the variance contributions results, the cross-correlation plots indicate that regional economic growth became more synchronized during the recent "Great Recession". There is an intrinsic connection between these time-varying average correlations and the stochastic volatility of the common national factor. For instance, an increasing volatility of the common factor tends to increase the correlations and thus the co-movement among all series, ceteris paribus. This connection helps to understand the impact of the economic uncertainty on the co-movement among all series. At the same time, the dynamics of these timevarying correlations in general also depend on the changing loading parameters and the stochastic volatility of the idiosyncratic factors. Therefore, these computed time-varying correlations concisely document the time-varying co-movement among all series by taking into account all elements of the model.

After having recovered the common factors for measuring economic activity and stochastic volatilities, we now use the QQ regressions to analyze the ability of LEPU to predict the movements in the common factors. The results are reported in Figures 9 to 12. As it can be seen from Figures 9 and 11, the impact of various quantiles of lagged LEPU, i.e., (LEPUt-1) is negative and statistically significant over the quantiles of the common factor for economic activity of the MSAs and the real personal income growth of the states, respectively. For the MSAs, the impact is relatively statistically stronger at moderately lower quantiles (i.e., 0.300.45) and upper quantiles (i.e., 0.80-0.85) as well, with the latter effect being the strongest, when the changes in uncertainty occurs from its initial state corresponding to a high level (i.e., quantile range of 0.80-0.90). While for the states, qualitatively similar results are observed in the sense that stronger statistical effects are felt at lower and upper quantiles of the conditional distribution of the output growth, this tends to happen when the increases in EPU occurs from its initial state of low to normal, as given by the quantile range of 0.15 to 0.50 . In Figures 10 and 12, we observe that EPU causes an increase in the common stochastic volatilities of both MSAs and states, respectively. In case of the MSAs, the strongest statistical impact is felt at upper quantiles (i.e., 0.80-0.90) of the volatility corresponding to a change in EPU, given an initial state that represents its normal phase (i.e., quantile range of 0.45-0.50). For the common volatility of the states, results are qualitatively similar to that of the MSAs, i.e., stronger statistical effects are observed at upper quantiles of the volatility (i.e., 0.85-0.90), when the changes in lagged EPU occurs from its normal phase, i.e., (quantiles of 0.50-0.60). However, for very low, moderate, and very high-levels of EPU, the effect of EPU is statistically 
insignificant on the volatility of output of the US states, unlike the MSAs for which the impact is always statistically significant, which in turn, could be an indication of more homogeneity amongst the MSAs relative to the states. ${ }^{11}$ Hence clearly, there is no one-to-one correspondence between the results of the states and MSAs, as subtle differences do exists and motivates our decision to go beyond the states and also look at the MSAs.

In sum, our results suggest that EPU negatively influences the common movements in economic activity in both MSAs and states, irrespective of whether the regional economies are in recession (lower quantiles) or expansion (upper quantiles). However, the initial state from where the uncertainty is changing is also important, with the effect being statistically strongest for the MSAs when EPU is already quite high, while for the states, this is the case, with EPU being in a low to normal initial state-zone. ${ }^{12}$ In other words, to circumvent the negative influence of uncertainty on the co-movements of the MSAs and states, policymakers will need to implement regime-dependent policies, which are aimed at removing tail risks, channel funds towards the private sector, and undo the "wait-and-see" attitudes by creating incentives to spend more strongly during not only periods of recession (as discussed, for example, in Blanchard (2009), Caggiano et al., (2014a, 2014b, 2016, 2017), and Gupta et al., (forthcoming)), but also when the economy is expanding, following movements in uncertainty . But, to determine the strength of the stimulus, i.e., the degree of intervention, policymakers should also have knowledge about the existing levels of uncertainty, since as we show the negative effects are strongest for MSAs when uncertainty is already quite high, while for states, this is the case at lower levels of the same. In other words, policymakers should have exact information about the current state of the economy-wide uncertainty, which in turn, would require accurate measures of this latent variable. ${ }^{13}$ Hence, importantly, it is not only the current state of the regional

\footnotetext{
11 The corresponding $t$-statistics from the standard quantile regressions have been plotted in Figure A1 of the Appendix. As with the QQ model, EPU tends to predict a reduction in output growth and increase in volatility for both the MSAs and states. But in this case, unlike the QQ approach, we are not able to observe, the additional dimension of how the effect of EPU is also contingent on the initial levels from which the same changes.

${ }^{12}$ As suggested by an anonymous referee, in Figures A2 to A5, we have now plotted the responses of the factors capturing the common output growth and volatility across US MSAs and states. Note that the pattern of the responses, in general, is similar to those depicted by the $t$-statistics plotted in Figures 9 through 12. Since, we are dealing with factors here, and following the extant literature (see for example, Kishor and Neanidis (2015), and Neely and Rapach $(2011,2015)$ among others) that relates common comovements of large number of variables with predictors, we just concentrate on the ability of these predictors to statistically explain the movements in the factors. In other words, we do not want to emphasize too much on the size of the impact of uncertainty on these common factors, as they are not necessarily indicating the effect on the underlying output growth and volatilities of the individual states and MSAs.

${ }^{13}$ Based on the suggestions of two anonymous referees, we also checked for the robustness of our results using alternative measures of uncertainty. In this regard, we used the VIX capturing financial market uncertainty, the economy-wide uncertainty of Jurado et al., (2015), and also the common stochastic volatility, as well as the crosssectional median of the idiosyncratic volatility over time recovered from the estimation of the DFV-TV-SV model. Understandably, when using the last two measures of uncertainty derived from the DFM-TV-SV model, we only look at its impact on the common component of output growth. In general, our results were qualitatively similar (which is not surprising given that the correlation of EPU with these other measures of uncertainty is statistically significant and above 30 percent consistently), but not so quantitatively. Complete details of these results are available upon request from the authors. However, at this stage, it is important to point out that, since we use a QQ predictive regression framework, it is important to work with a measure of uncertainty that is exogenous, given estimation issues associated with endogenous predictors. In this regard, while there is a large literature associated with endogeneity of predictors, and alternative ways of circumventing these problems in standard predictive regression framework (see, Narayan and Gupta (2015) for a detailed discussion in this regard), we are unaware of estimation approaches developed under the QQ model to tackle this issue. Given this, we performed standard Granger causality tests, and detected that barring EPU, all the alternative measures of uncertainty used above were caused by common growth and volatility of the MSAs and states. Endogeneity of model-based measures of
} 
economies, but also the existing levels of uncertainty, that will determine not only the strength of the policies, but also whether, at that point in time, the emphasis should be on the MSAs or the states. Our results also suggest that, when changes in EPU occur from its initial normal phase, and if uncertainty of economic activity in the regional economies is already high, then this is likely to make the regional economies simultaneously highly volatile. Hence, if volatility is a concern for policymakers, policies will again need to be state-dependent, i.e., contingent on levels of volatility and uncertainty simultaneously.

\section{Conclusion}

In the wake of the "Great Recession”, a large number of studies have analyzed the impact of uncertainty on national economies around the world. Given this, the objective of this paper is to analyze, for the first time, the role of a news-based measure of economic policy uncertainty (EPU) in explaining common business cycles and volatilities in the 48 contiguous US states and 51 largest MSAs separately, over the quarterly period of 1948:Q1 to 2014:Q4, and the monthly period of 1990:M1 to 2015:M12, respectively. In this regard, to capture potential timevarying co-movement among the output measures of US states and MSAs, we first estimate a dynamic factor model which allows for time-varying loadings and stochastic volatility (DFMTV-SV). In the second step, we use a quantile-on-quantile (QQ) predictive regression model to capture the effect of uncertainty on the common factor and stochastic volatility derived from the DFM-TV-SV for the states and MSAs.

Our results from the DFM-TV-SV highlight the importance of the national factors in driving economic activity and stochastic volatility of the regional economies. The QQ model indicates that EPU negatively and, in a statistically significant fashion, affects the national factors of economic activity. Moreover, EPU also has a significant positive influence on the common factors of volatility for both the states and MSAs. While these results hold over the entire quantile range of both the dependent and independent variables, the size of the impact of EPU is contingent on the initial state of both the common factors and uncertainty. Therefore, policymakers should not only need to devise policies that are state-dependent, but also have appropriate measures of uncertainty to gauge its current level.

While the QQ model allows us to predict the effect of uncertainty on common business cycles and volatilities of US MSAs and states contingent on the current size of both the dependent variable (business cycles and volatilities) and its predictor, we are unable to analyze the dynamic impact of uncertainty shocks using this predictive regression framework. In this regard, one could extend the analysis to consider a quantile structural VAR (as in Gupta et al., (forthcoming)) to identify the regime-dependent impact of the uncertainty shocks (based on already available estimates of (exogenous or endogenous measures of) uncertainty), given the latter's own state from which the shock hits the economy. ${ }^{14}$ Alternatively, one could use volatility-in-mean effects from large-scale time-varying factor models with stochastic volatility

\footnotetext{
uncertainty has also been discussed in detail in Ludvigson et al., (2015). Given this, and since we are at this stage drawing inferences from the QQ model, we consider the results based on EPU to be relatively more reliable.

${ }^{14}$ We conducted a preliminary analysis by creating two series each for output, LSV and LEPU based on the values at each point in time being above and below their unconditional median. Using a VAR analysis, based on these series, a positive shock to LEPU, with the same ordered first in the VAR due to its exogeneity, led to a reduction in MSA- or state-level output and increase in LSV, irrespective of whether the series considered were below or above their respective unconditional medians. These results do provide support for the predictive regression analysis from a dynamic perspective following a shock to uncertainty. Complete details of these results are available upon request from the authors.
} 
to analyze the impact of model-generated uncertainty shocks (see for example, Mumtaz and Zanetti (2013), Mumtaz et al., (2016), Carriero et al., (forthcoming), and Creal and Wu (forthcoming) among others). 


\section{References}

Aguiar-Conraria, L., P. Brinca, H.V., Guðjónsson, and M.J. Soares (2017) "Business cycle synchronization across U.S. states," The B.E. Journal of Macroeconomics, 17(1), 1-17.

Arias, M.A., C.S. Gascon, and D.E. Rapach (2016). "Metro Business Cycles", Journal of Urban Economics, 94, 90-108.

Artis, M., C. Dreger, and K. Kholodilin (2011). What drives regional business cycles? The role of common and spatial components," The Manchester School, 79(5), 1035-1044.

Azzimonti, M. (2018). "Partisan conflict and private investment.” Journal of Monetary Economics, 23, 114-131..

Bachmann, R., Elstner, S., and Sims, E. (2013). "Uncertainty and economic activity: Evidence from business survey data,” American Economic Journal: Macroeconomics 5, 217 - 249.

Baker, S., Bloom, N., and Davis, S. (2016). "Measuring economic policy uncertainty," Quarterly Journal of Economics, 131, 1593 - 1636.

Balcilar, M., Demirer, R., Gupta, R., and van Eyden, R. (Forthcoming). "Effectiveness of monetary policy in the Euro area: The role of US economic policy uncertainty," Journal of Policy Modeling.

Balcilar, M., Gupta, R., and Jooste, C. (2017). "Long memory, economic policy uncertainty, and forecasting US inflation: a Bayesian VARFIMA approach,” Applied Economics, 49, 1047 1054.

Balcilar, M., Gupta, R., and Segnon, M. (2016). "The Role of economic policy uncertainty in predicting U.S. recessions: A mixed-frequency Markov-switching vector autoregressive approach,” Economics: The Open-Access, Open-Assessment E-Journal, 10, (2016-27), 1 - 20.

Bali, T. G., Brown, S. J., and Tang, Y. (2015). "Macroeconomic uncertainty and expected stock returns," Georgetown McDonough School of Business, Research Paper No. 2407279.

Basu, S., and Bundick, B. (2014). "Uncertainty shocks in a model of effective demand," Federal Reserve Bank of Kansas City, Research Working Paper No., 14 - 15.

Berger, T., Grabert, S., and Kempa, B. (2017). “Global macroeconomic uncertainty,” Journal of Macroeconomics, 53, 42-56.

Bernanke, B. S. (1983). "Irreversibility, uncertainty, and cyclical investment," Quarterly Journal of Economics, 98, 85 - 106.

Bhatt, V., N. K. Kishor, and J. Ma (2017), “The Impact of EMU on Bond Yield Convergence: Evidence from a Time-Varying Dynamic Factor Model,” Journal of Economic Dynamics and Control, 82, 206-222.

Blanchard, O. (2009). (Nearly) nothing to fear but fear itself. The Economist, Economics focus (guest article), January 29.

Bloom, N. (2009). “The impact of uncertainty shocks,” Econometrica, 77, 623 - 685.

Bloom, N., Floetotto, M., Jaimovich, N., Saporta-Eksten, I., and Terry, S. J. (2014). "Really uncertain business cycles," Stanford University, Mimeo.

Brogaard, J. and Detzel, A. (2015). "The asset-pricing implications of government economic policy uncertainty,” Management Science, 61, 3 - 18.

Caggiano, G., Castelnuovo, E., and Figueres, J.M. (2016). "Economic policy uncertainty spillovers in booms and busts," University of Padova and University of Melbourne, Mimeo.

Caggiano, G., Castelnuovo, E., and Figueres, J.M. (2017). "Economic policy uncertainty and unemployment in the United States: A nonlinear approach,” Economics Letters, 151, 31 - 34.

Caggiano, G., Castelnuovo, E., and Groshenny, N. (2014a). "Uncertainty shocks and unemployment dynamics in US recessions,” Journal of Monetary Economics, 67, 78 - 92.

Caggiano, G., Castelnuovo, E., and Nodari, G. (2014b). "Uncertainty and monetary policy in good and bad times,” University of Padoa, Dipartimento di Scienze Economiche, Marco Fanno, Working Paper No. 0188. 
Caldara, D., Fuentes-Albero, C., Gilchrist, S., and Zakrajšek, E. (2016). The macroeconomic impact of financial and uncertainty shocks. European Economic Review, 88, 185-207.

Caldara, D., and Iacoviello, M. (2016). "Measuring geopolitical risk," Working Paper, Board of Governors of the Federal Reserve Board.

Carlino, G.A. and R.H. DeFina (2004). "How Strong is Co-Movement in Employment Over the Business Cycle? Evidence from State/Sector Data," Journal of Urban Economics, 55, 298-315.

Carriero, A. Clark, T., and Marcellino, M. (Forthcoming). "Measuring uncertainty and its impact on the economy," The Review of Economics and Statistics, forthcoming.

Carriero, A., Mumtaz, H., Theophilopoulou, A., and Theodoridis, K. (2015). "The impact of uncertainty shocks under measurement error: A proxy SVAR approach,” Journal of Money, Credit and Banking, 47, 1223 - 1238.

Castelnuovo, E., Caggiano, G., and Pellegrino, G. (2015). "Estimating the real effects of uncertainty shocks at the zero lower bound,” University of Padoa, Dipartimento di Scienze Economiche, "Marco Fanno" Working Paper No. 0200.

Cheng, C.-H. J., Hankins, W. A., and Chiu, C.-W. J. (2016). "Does US partisan conflict matter for the Euro area?” Economics Letters, 138, 64 - 67.

Choi, S. (2017). "Variability in the effects of uncertainty shocks: New stylized facts from OECD countries," Journal of Macroeconomics, 53, 127-144.

Christiano, L., Motto, R., and Rostagno, M. (2014). "Risk shocks,” American Economic Review, 104, $27-65$.

Chuliá, H., Guillén, M., and Uribe, J.M. (2017). "Measuring uncertainty in the stock market," International Review of Economics and Finance, 48, 18 - 33.

Cogley, T. and T. Sargent (2005), "Drifts and Volatilities: Monetary Policies and Outcomes in the Post WWII US,” Review of Economic Dynamics, Vol. 8, Issue 2, 262-302.

Colombo, V. (2013). "Economic policy uncertainty in the US: Does it matter for the Euro area?," Economics Letters, 121, $39-42$.

Creal, D. D. and Wu, C. (Forthcoming). "Monetary policy uncertainty and economic fluctuations," International Economic Review.

Crone, T.M. (2005). "An Alternative Definition of Economic Regions in the United States Based on Similarities in State Business Cycles," Review of Economics and Statistics, 87, 617-626.

Del Negro, M and C. Otrok (2008), "Dynamic Factor Models with Time-Varying Parameters: Measuring Changes in International Business Cycles,” Federal Reserve Bank of New York Staff Report, 326.

Del Negro, M and G. Primiceri (2015), "Time Varying Structural Vector Autoregressions and Monetary Policy: A Corrigendum,” Review of Economic Studies, 82(4), 1342-1345.

Dew-Becker, I., Giglio, S., and Kelly, B. (2017). How do investors perceive the risks from macroeconomic and financial uncertainty? Evidence from 19 option markets. Yale University, Mimeo.

Dixit, A. K., and Pindyck, R. S. (1994). “Investment under uncertainty”. Princeton University Press. Princeton, New Jersey.

Fernández-Villaverde, J., Guerrón-Quintana, P., Rubio-Ramírez, J. F., and Uribe, M. (2011). “Risk matters: The real effects of volatility shocks," American Economic Review, 101, 2530 - 2561.

Ghent, A., and M.T. Owyang (2010). "Is Housing the Business Cycle? Evidence from U.S. Cities," Journal of Urban Economics, 67(3), 336-351.

Giglio, S., Kelly, B., and Pruitt, S. (2016). Systemic risk and the macroeconomy: An empirical evaluation. Journal of Financial Economics, 119, 457-471.

Gourio, F. (2012). “Disaster risk and business cycles,” American Economic Review, 102, 2734 - 2766.

Gupta, R., and Jooste, C. (Forthcoming). "Unconventional monetary policy shocks in OECD Countries: How important is the extent of policy uncertainty?” International Economics and Economic Policy. 
Gupta, R., Lau, C-K-M., Wohar, M.E. (Forthcoming). "The impact of US uncertainty on the Euro area in good and bad times: Evidence from a quantile structural vector autoregressive model," Empirica.Istrefi, K., and Piloiu, A. (2015). "Economic policy uncertainty and inflation expectations," Banque de France, Mimeo.

Johannsen, B. K. (2013). "When are the effects of fiscal policy uncertainty large?," Northwestern University, Mimeo.

Jones, P. M., and Enders, W. (2016). "The asymmetric effects of uncertainty on macroeconomic activity,” Macroeconomic Dynamics, 20, 1219 - 1246.

Jones, P. M., and Olson, E. (2013). "The time-varying correlation between uncertainty, output and inflation: Evidence from a DCC-GARCH model,” Economics Letters, 118, 33 - 37.

Jones, P. M., and Olson, E. (2015). “The international effects of US uncertainty,” International Journal of Finance and Economics, 20, 242 - 252.

Jurado, K., S.C. Ludvigson, and S. Ng (2015) "Measuring Uncertainty," The American Economic Review, 105(3), 1177-1215.

Kang, W., Lee, K., and Ratti, R. A. (2014). "Economic policy uncertainty and firm-level investment," Journal of Macroeconomics, 39, 42 - 53.

Karnizova, L. and Li, J. C. (2014). "Economic policy uncertainty, financial markets and probability of US recessions,” Economics Letters, 125, 261 - 265.

Kim, C. and C. R. Nelson (1999), State-Space Models with Regime Switching, Cambridge, MA, MIT Press.

Kim, S., N. Shephard, and S. Chib (1998), "Stochastic Volatility: Likelihood Inference and Comparison with ARCH Models,” Review of Economic Studies, 65, 361-393.

Kishor, K.N., Neanidis, K. (2015). What is Driving Financial Dollarization in Transition Economies? A Dynamic Factor Analysis. Macroeconomic Dynamics, 19, 816-835.

Koop, G. and D. Korobilis (2010), "Bayesian Multivariate Time Series Methods for Empirical Macroeconomics," Foundations and Trends in Econometrics, 3, 267-358.

Larsen, V.H. (2017). “Components of uncertainty,” Norges Bank, Working Paper No. 05/2017.

Leduc, S., and Liu, Z. (2013). "Uncertainty shocks are aggregate demand shocks,” Federal Reserve Bank of San Francisco, Working Paper, 2012 - 10.

Ludvigson, S. C., Ma, S., and Ng, S. (2015). "Uncertainty and business cycles: Exogenous impulse or endogenous response?,” National Bureau of Economic Research, Working Paper No. 21803.

Ma, L. and R. Koenker (2006). "Quantile regression methods for recursive structural equation models," Journal of Econometrics, 134, 471-506.

Manela, A. and Moreira, A. (2017). "News implied volatility and disaster concerns," Journal of Financial Economics, 123, 137 - 162.

Mumtaz, H. and Surico, P. (2013). "Policy uncertainty and aggregate fluctuations,” Queen Mary University of London, School of Economics and Finance, Working Paper No.708.

Mumtaz, H., and Theodoridis, K. (2017a). "The changing transmission of uncertainty shocks in the US: An empirical analysis,” Journal of Business and Economic Statistics, doi: http://dx.doi.org/10.1080/07350015.2016.1147357.

Mumtaz, H. and Theodoridis, K. (2017b). "Common and country specific economic uncertainty," Journal of International Economics, 105, 205 - 216.

Mumtaz, H., and Zanetti, F. (2013). “The impact of the volatility of monetary policy shocks,” Journal of Money, Credit and Banking, 45, 535 - 558.

Mumtaz, H., Sunder-Plassmann, L., and Theophilopoulou, A. (2016). "The state level impact of uncertainty shocks,” Queen Mary University of London, School of Economics and Finance, Working Paper No. 793.

Nakata, T. (2013). "Uncertainty at the zero lowerbound," Federal Reserve Board, Finance and Economics Discussion Series Working Paper, No., 2013 - 09. 
Narayan, P.K., and Gupta, R. (2015). Has Oil Price Predicted Stock Returns for Over a Century? Energy Economics, 48, 18-23.

Neely, C.J., and Rapach, D.E. (2011). International Comovements in Inflation Rates and Country Characteristics. Journal of International Money and Finance, 30(7), 1471-1490.

Neely, C.J., and Rapach, D.E. (2015). Common Fluctuations in OECD Budget Balances. Federal Reserve Bank of St. Louis Review, 97(2), 109-132.

Nodari, G. (2014). “Financial regulation policy uncertainty and credit spreads in the US," Journal of Macroeconomics, 41, 122 - 132.

Owyang, M.T. and H.J. Wall (2009). "Regional VARs and the Channels of Monetary Policy," Applied Economics Letters, 16(12), 1191-1194.

Owyang, M.T., D.E. Rapach, and H.J. Wall (2009). "States and the Business Cycle," Journal of Urban Economics, 65(2), 181-194.

Owyang, M.T., J. Piger, and H.J. Wall (2005). "Business Cycle Phases in U.S. States," Review of Economics and Statistics, 87, 604-616.

Owyang, M.T., J. Piger, and H.J. Wall (2008). "A State-Level Analysis of the Great Moderation," Regional Science and Urban Economics, 38(6), 578-589.

Partridge, M.D. and D.S. Rickman (2005). "Regional Cyclical Asymmetries in an Optimal Currency Area: An Analysis Using U.S. State Data," Oxford Economic Papers, 57, 373-397.

Primiceri, G. (2005), “Time Varying Structural Vector Autoregressions and Monetary Policy,” Review of Economic Studies, 72, 821-852.

Rossi, B., and Sekhposyan, T. (2015). "Macroeconomic uncertainty indices based on nowcast and forecast error distributions,” American Economic Review Papers and Proceedings, 105, 650 655.

Rossi, B., and Sekhposyan, T. (2017). "Macroeconomic Uncertainty Indices for the Euro Area and its Individual Member Countries,” Empirical Economics, 53(1), 41-62.

Rossi, B., Sekhposyan, T. and Soupre, M. (2016). "Understanding the sources of macroeconomic uncertainty,” Universitat Pompeu Fabra - Centre de Recerca en Economia Internacional (CREI), Mimeo.

Scotti, C. (2016). "Surprise and uncertainty indexes: Real-time aggregation of real-activity macro surprises," Journal of Monetary Economics, 82, 1 - 19.

Segnon, M., Gupta, R., Bekiros, S., and Wohar, M.E. (Forthcoming). "Forecasting US GNP growth: The role of uncertainty," Journal of Forecasting.

Sim, N. and A. Zhou (2015). "Oil prices, US stock return, and the dependence between their quantiles," Journal of Banking and Finance, 55, 1-8.

Stock, J. and M. Watson (2007), "Why Has U.S. Inflation Become Harder to Forecast?” Journal of Money, Banking and Credit, Vol. 39, No. 1, 3-33.

Stockhammar, P., and Österholm, P. (2016). "Effects of US policy uncertainty on Swedish GDP growth,” Empirical Economics, 50, 443 - 462.

Stockhammar, P., and Österholm, P. (2017). "The Impact of US Uncertainty Shocks on Small Open Economies,” Open Economies Review, 28, 347 - 368. 
Figure 1. National Factor of the Economic Activity Indices of the 51 MSAs

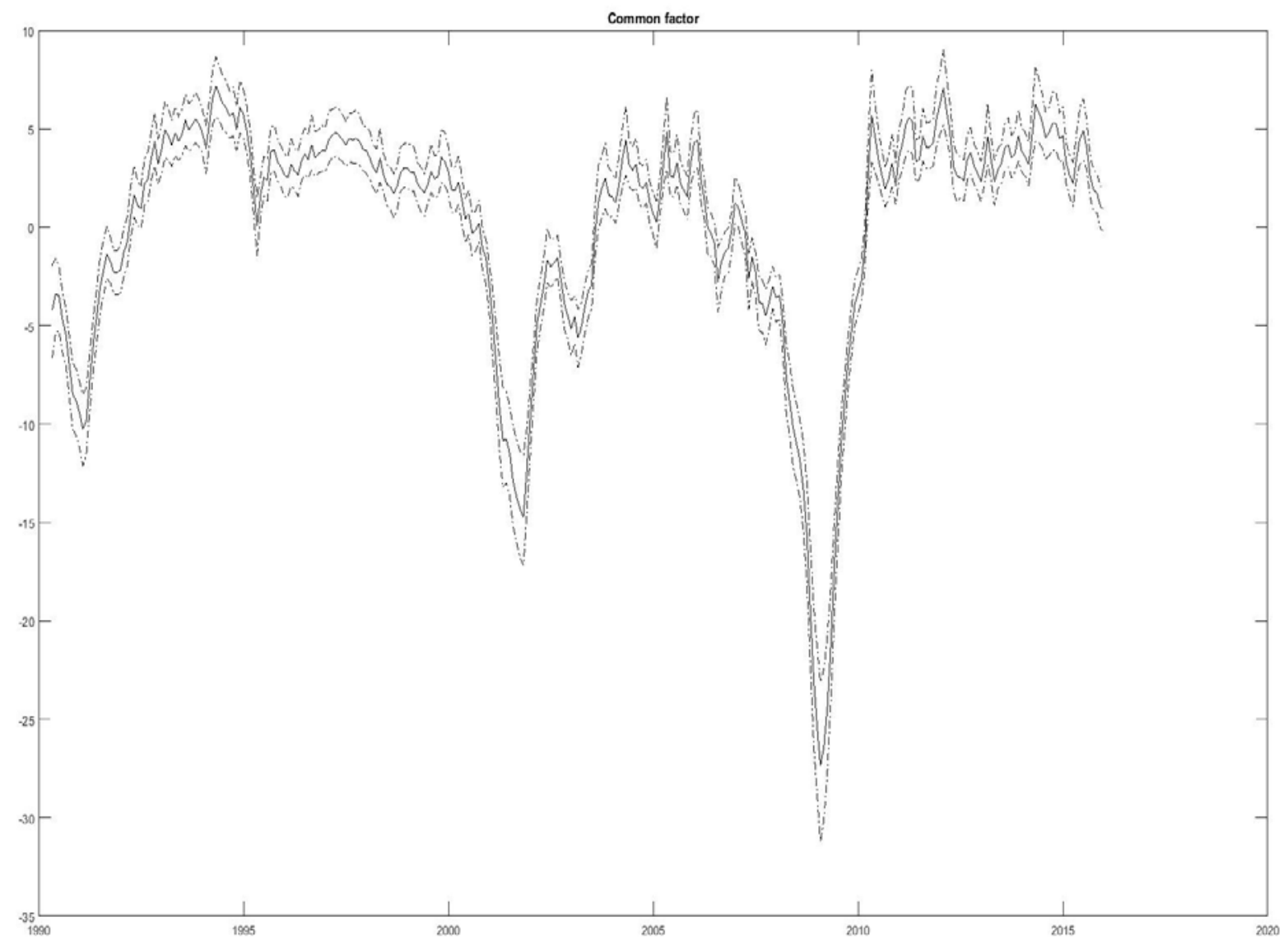


Figure 2. Variance Contributions of the National Factor for the 51 MSAs
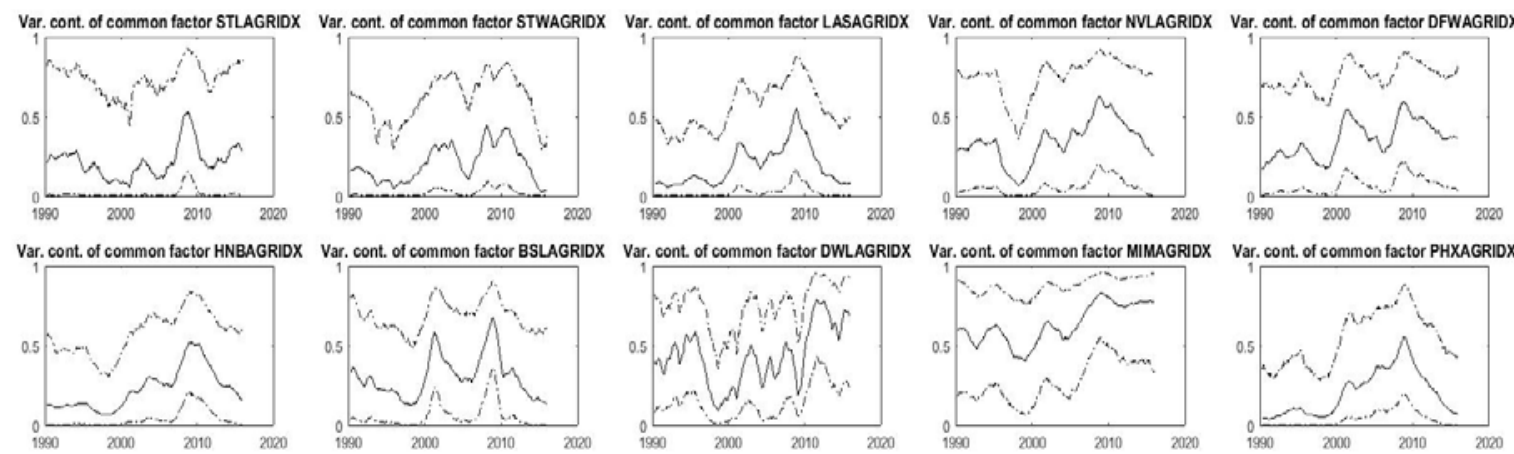

Var. cont. of common factor PHXAGRIDX

Var. cont. of common factor SFCAGRIDX
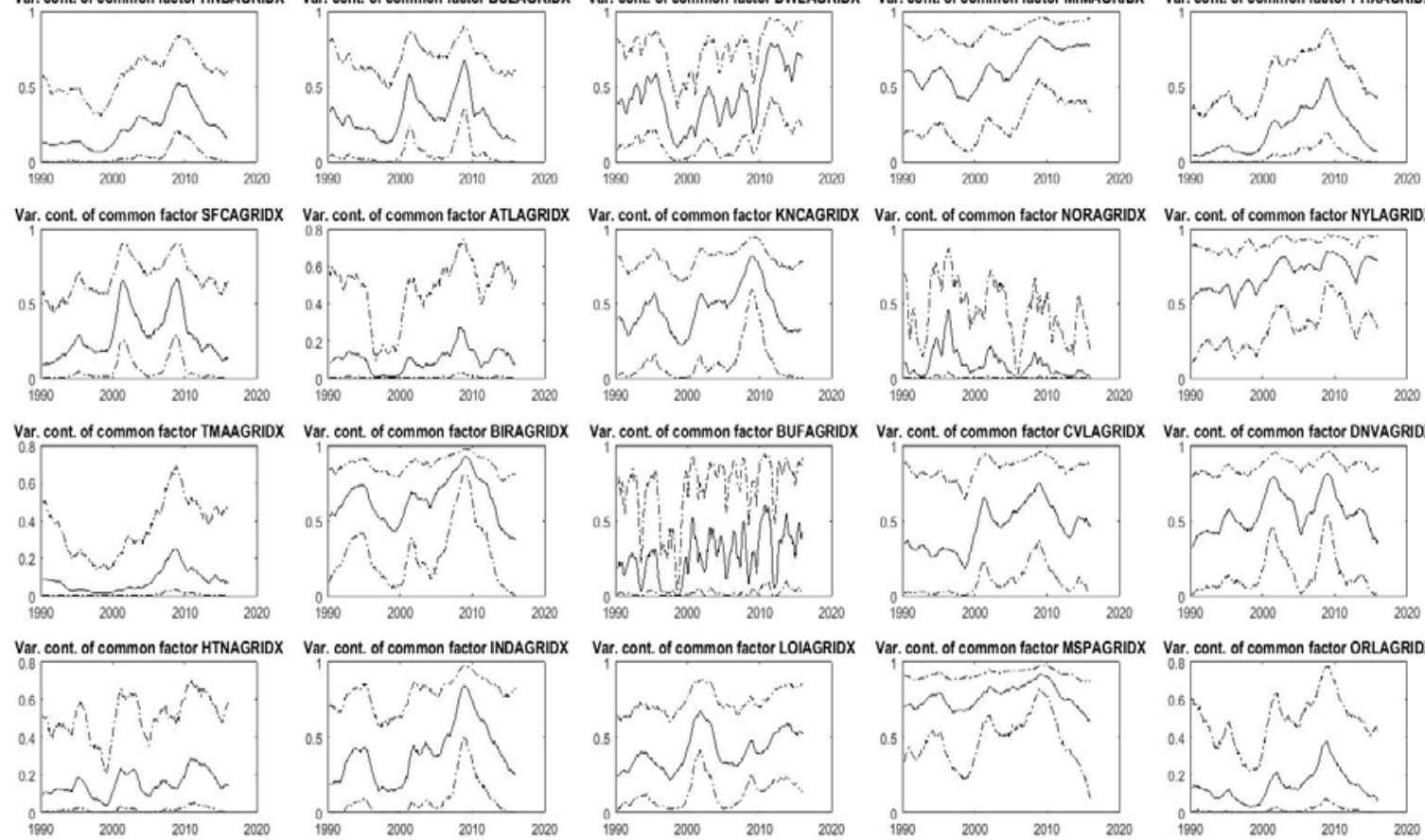
Figure 2. Variance Contributions of the National Factor for the 51 MSAs (Continued)
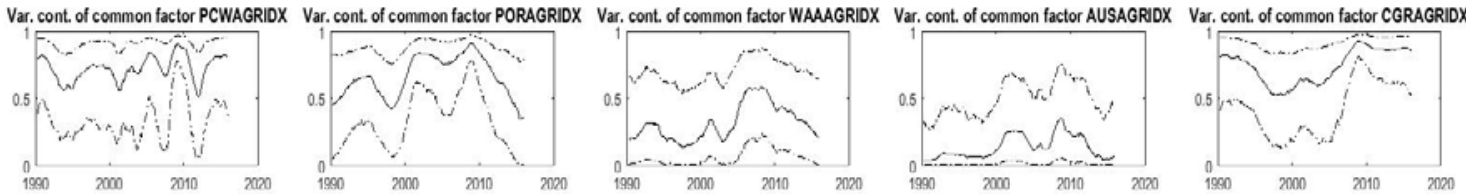

Var. cont. of common factor CHIAGRIDX
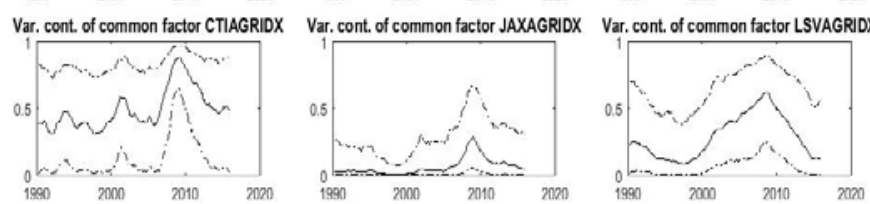

Var. cont. of common factor MWKAGRIDX

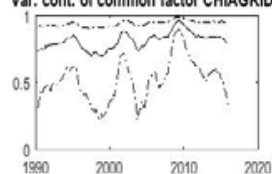

Var. cont. of common factor OKCAGRIDX

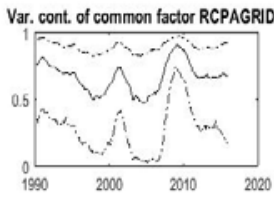

Var. cont. of common factor SDIAGRIDX
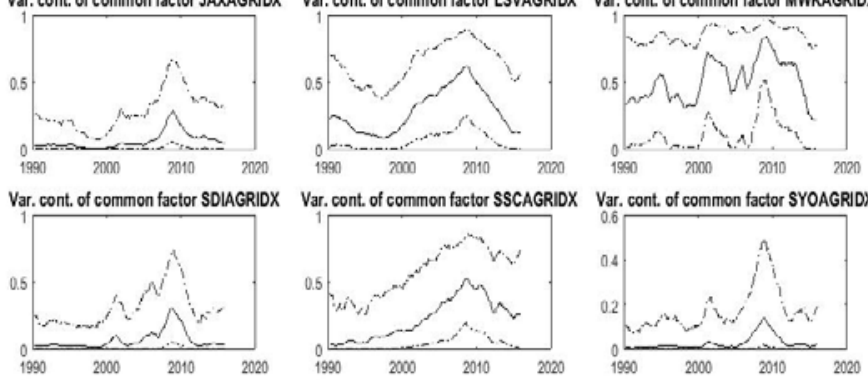

Var. cont. of common factor SYOAGRIDX

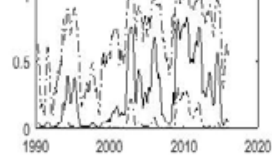

Var. cont. of common factor LRSAGRIDX

Var. cont. of common factor NFKAGRIDX

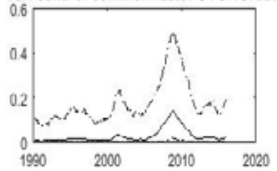

Var. cont. of common factor BTMAGRIDX Var. cont. of common factor COLAGRIDX
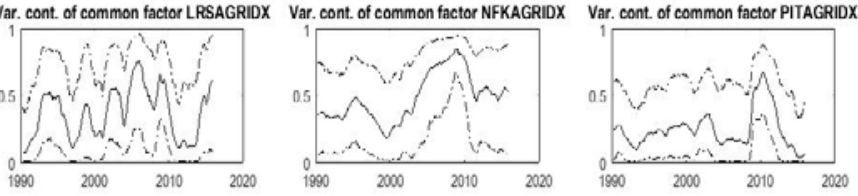

Ver. cont of common fintor PPWAGRIDX Var. cont of common foctor RCYAGRIDX
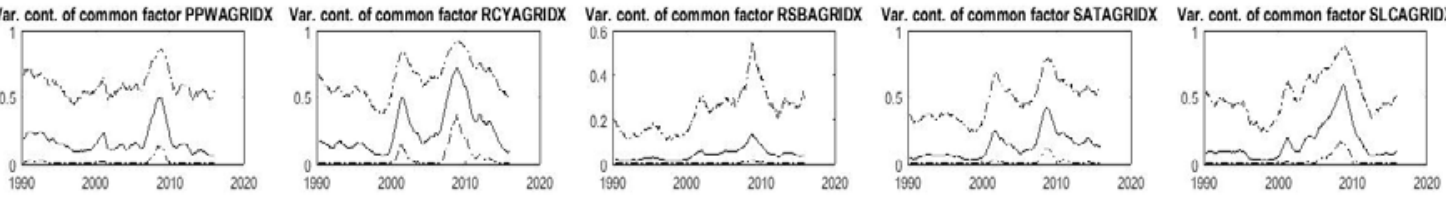

Var. cont. of common factor MPHAGRIDX

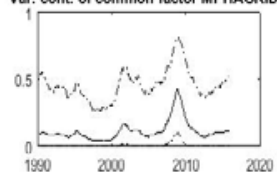


Figure 3. Stochastic Volatility of the National Factor for the 51 MSAs

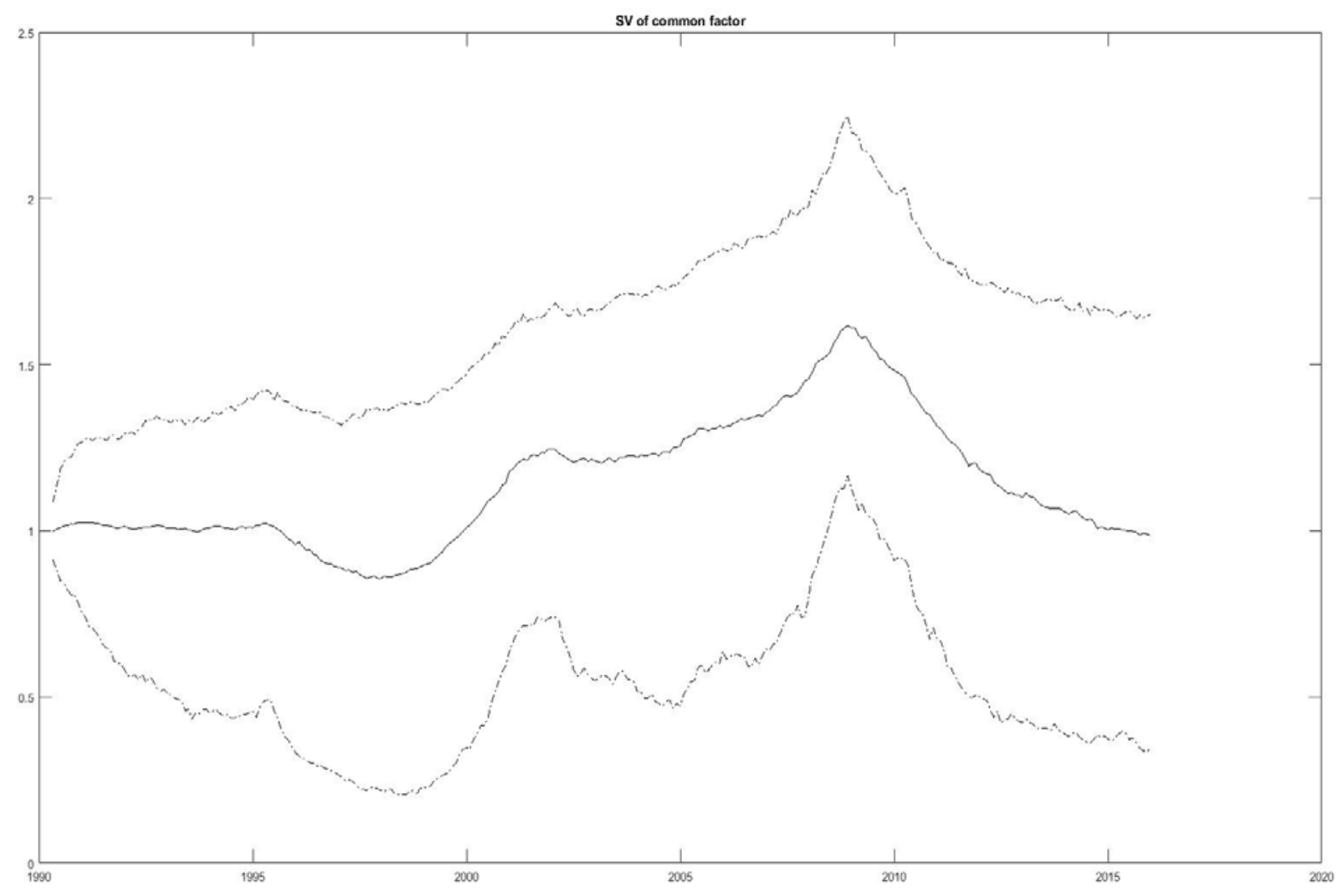


Figure 4. Average Cross-Correlation of Economic Activity Indices in 51 MSAs

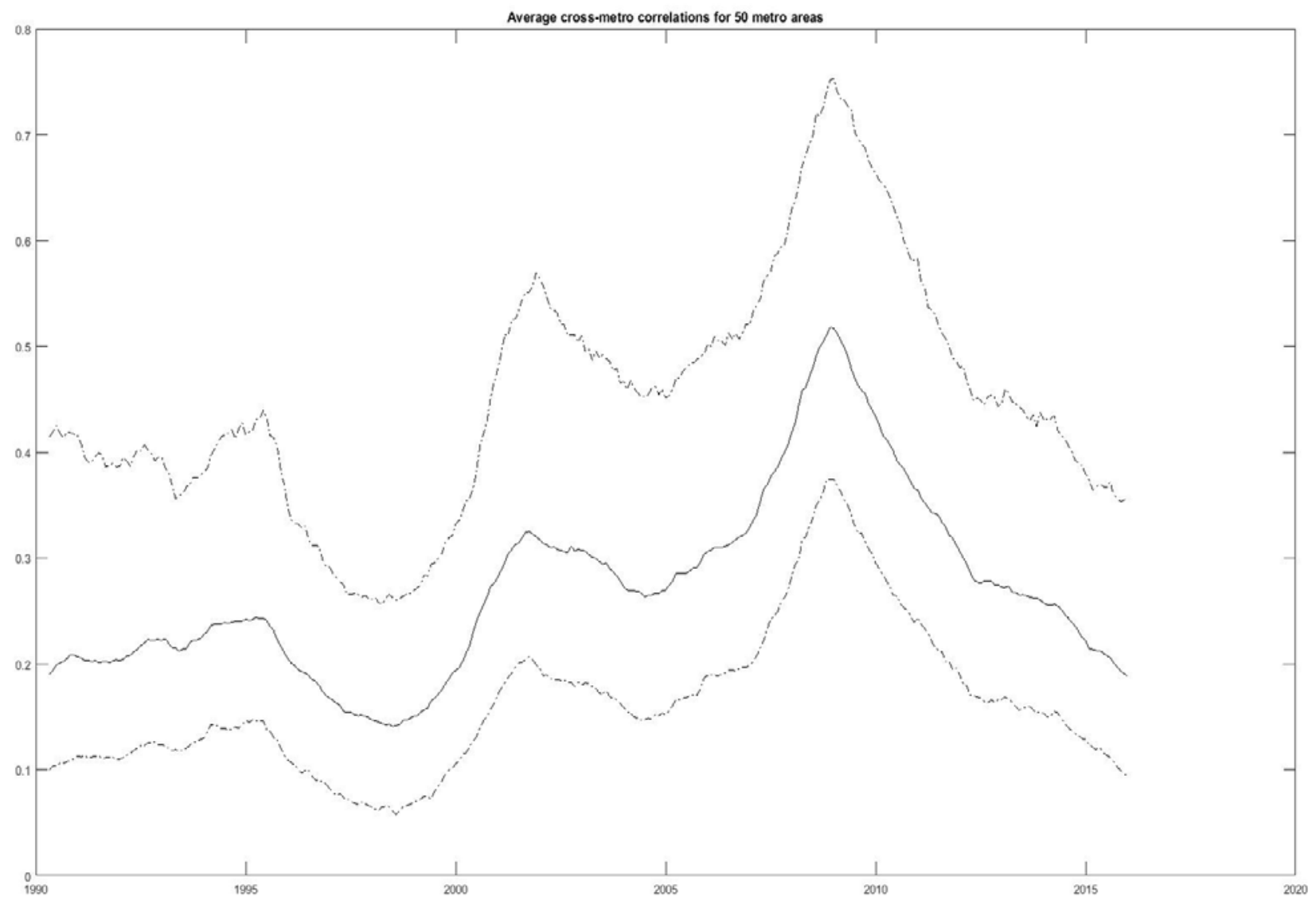


Figure 5. National Factor of Real Personal Income Growth for the 48 States

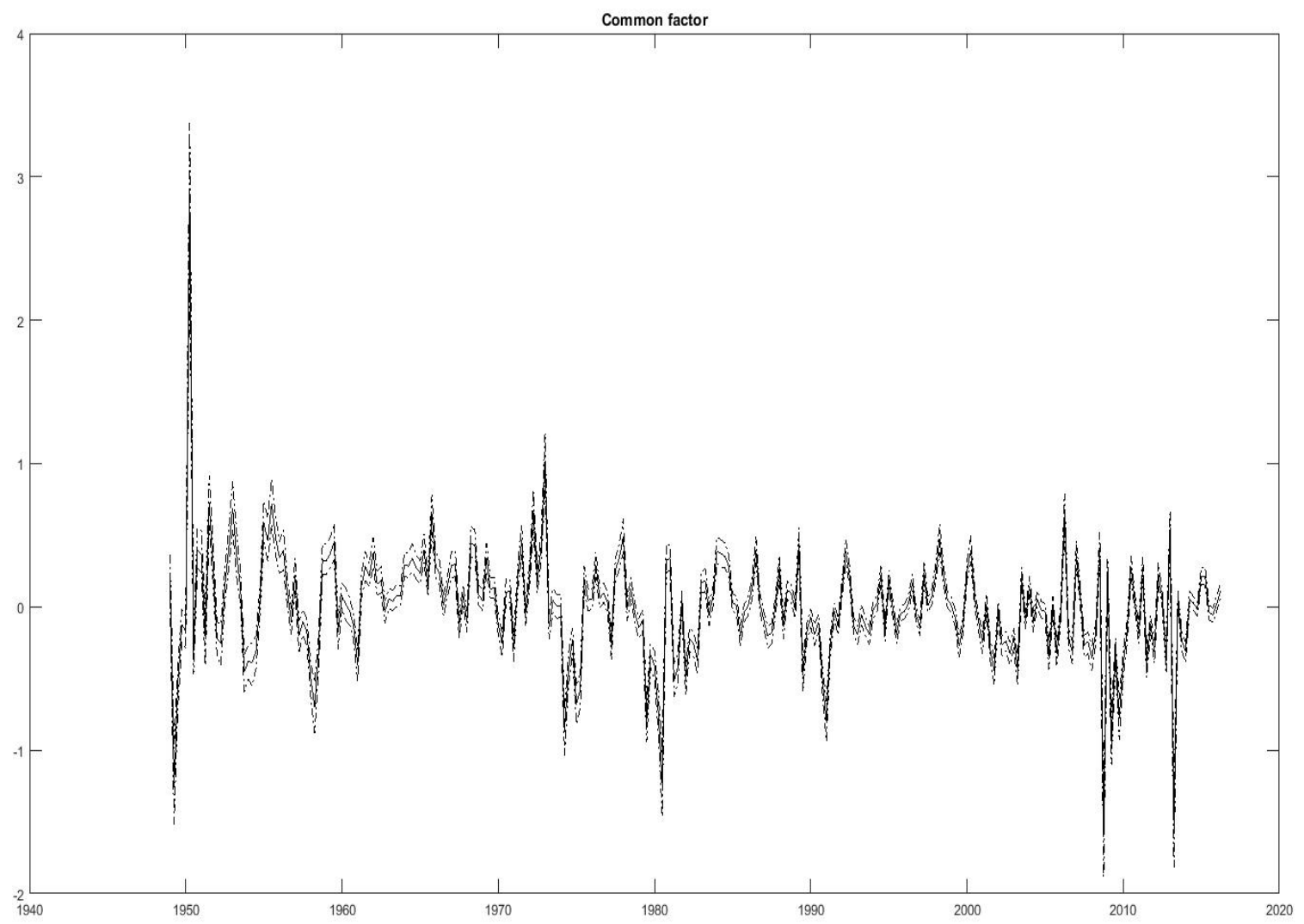


Figure 6. Variance Contributions of the National Factor for the 48 States
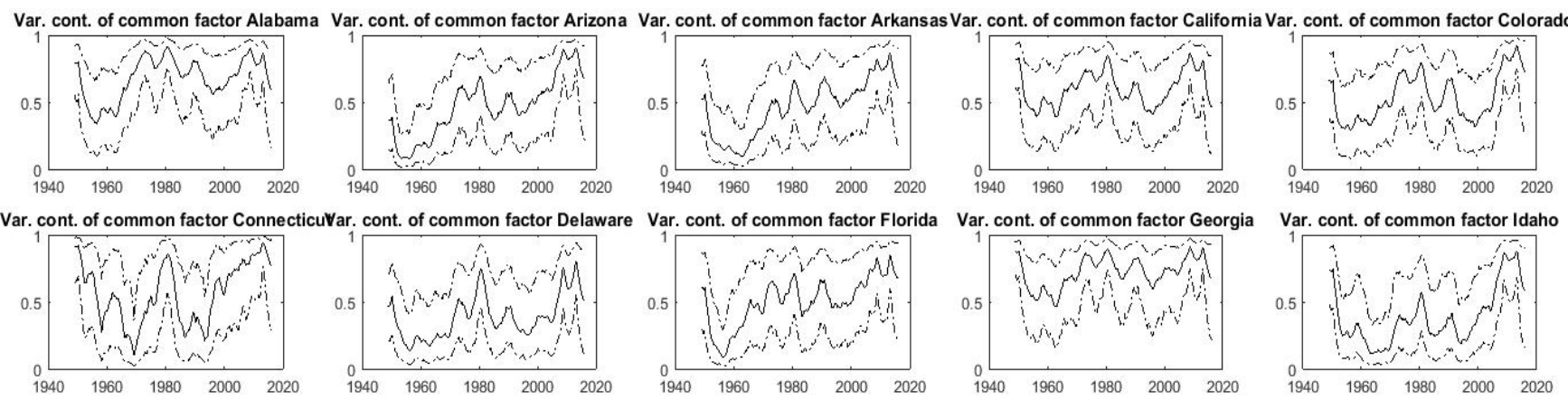

Var. cont of common factor Idaho
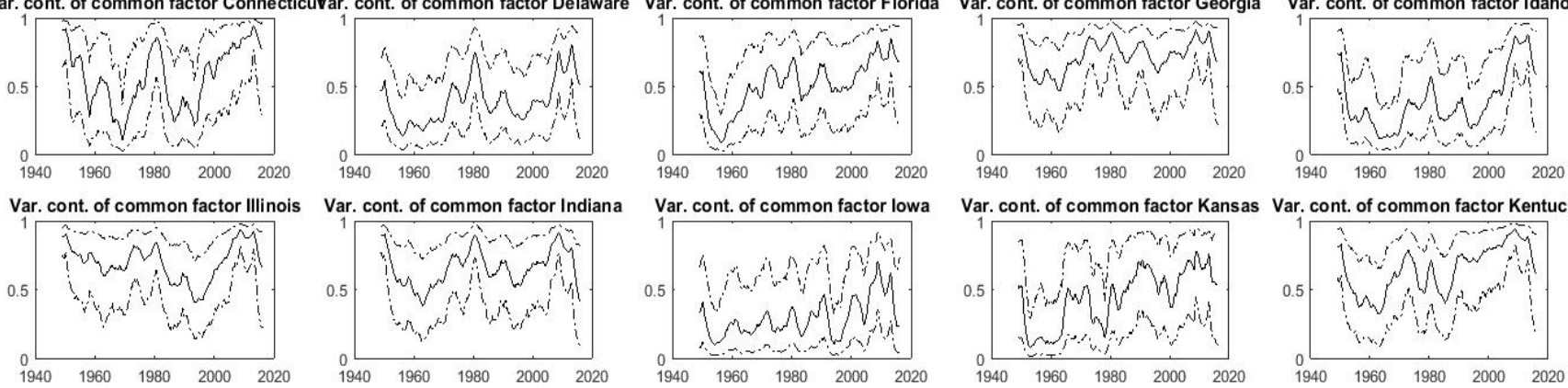

Var. cont. of common factor Kansas Var. cont. of common factor Kentucky
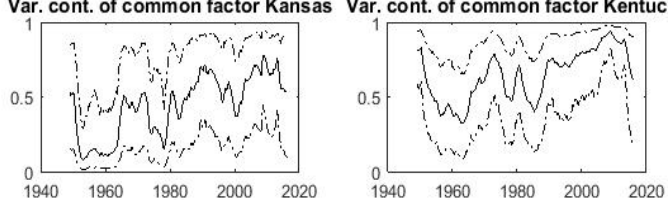

Var. cont. of common factor Louisiana Var. cont. of common factor Maine
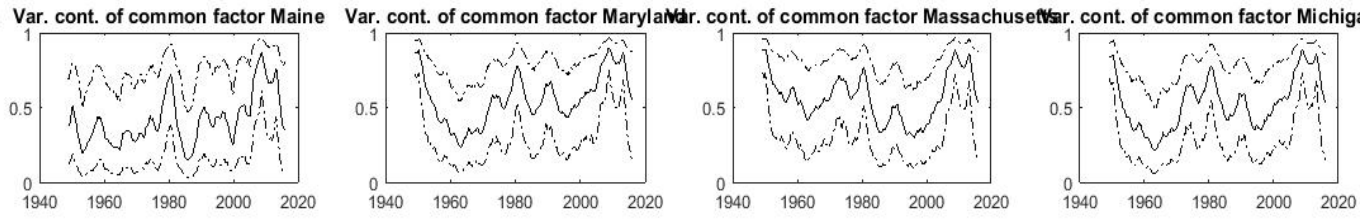

Var. cont. of common factor Montana Var. cont. of common factor Nebraska
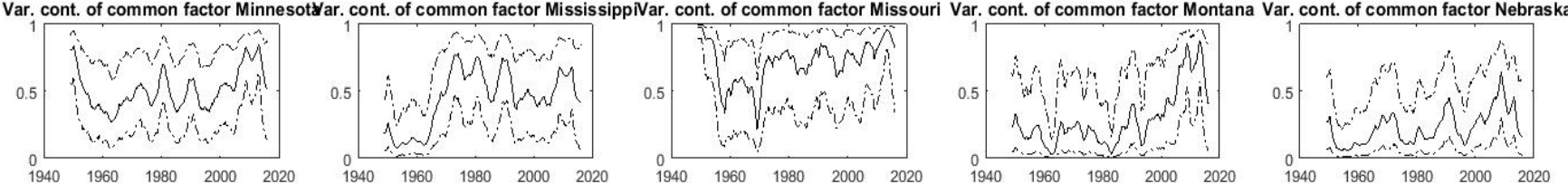
Figure 6. Variance Contributions of the National Factor for the 48 States (Continued)

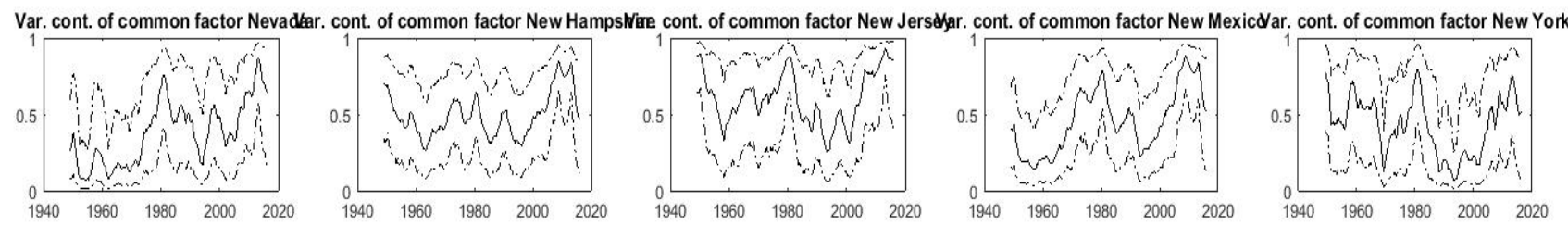

Var. cont. of common factor North Cardima cont. of common factor North Da

Var. cont. of common factor Oregon
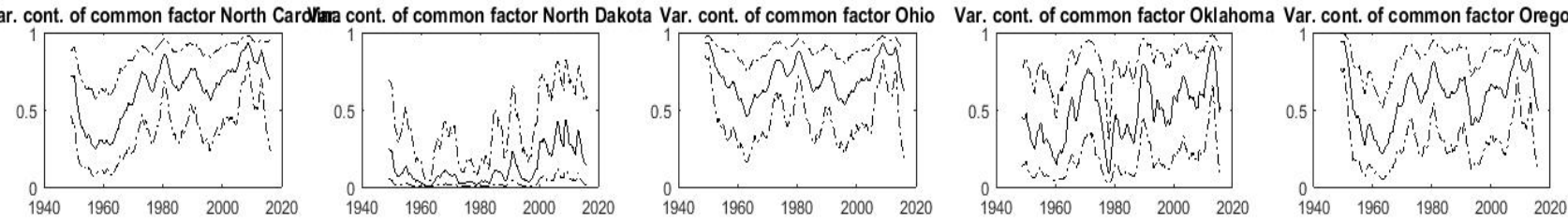

Var. cont. of common factor Pennsylvakhia. cont. of common factor Rhode Iskad cont. of common factor South Cardlaracont. of common factor South Dakoltar. cont. of common factor Tennessee
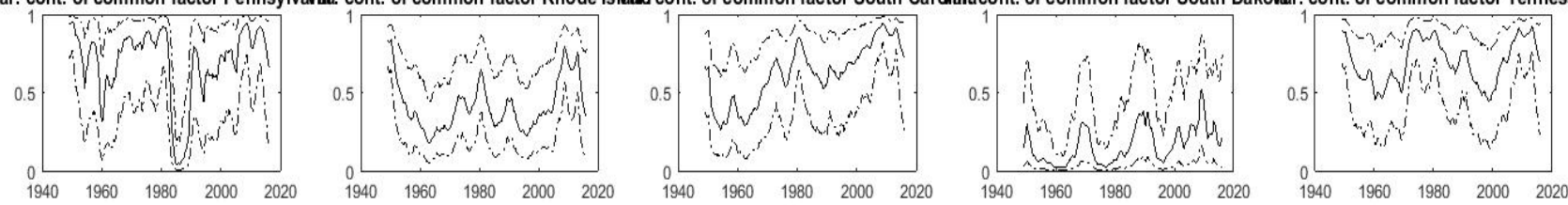

Var. cont. of common factor Texas

Var. cont of common factor Utah

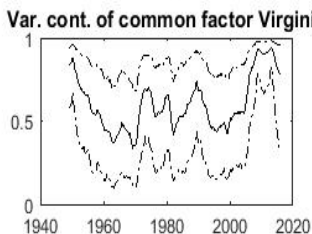

cont of common factor Washington
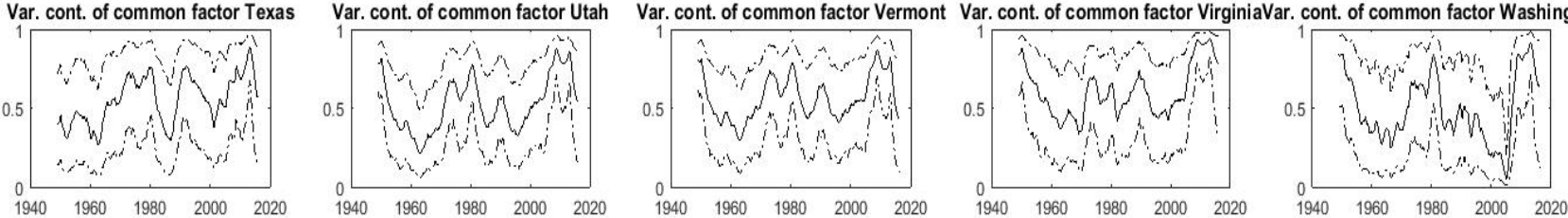

Var. cont. of common factor West VirginVar. cont. of common factor WisconsinVar. cont. of common factor Wyoming
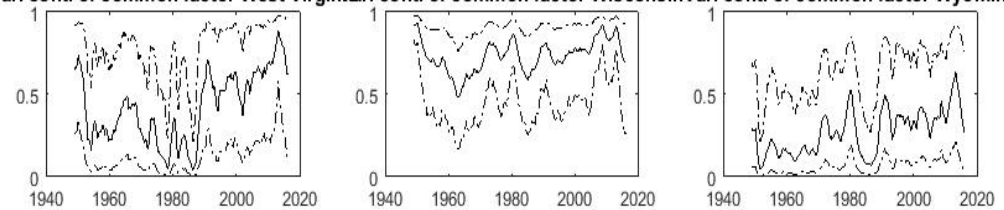
Figure 7. Stochastic Volatility of the National Factor for the 48 States

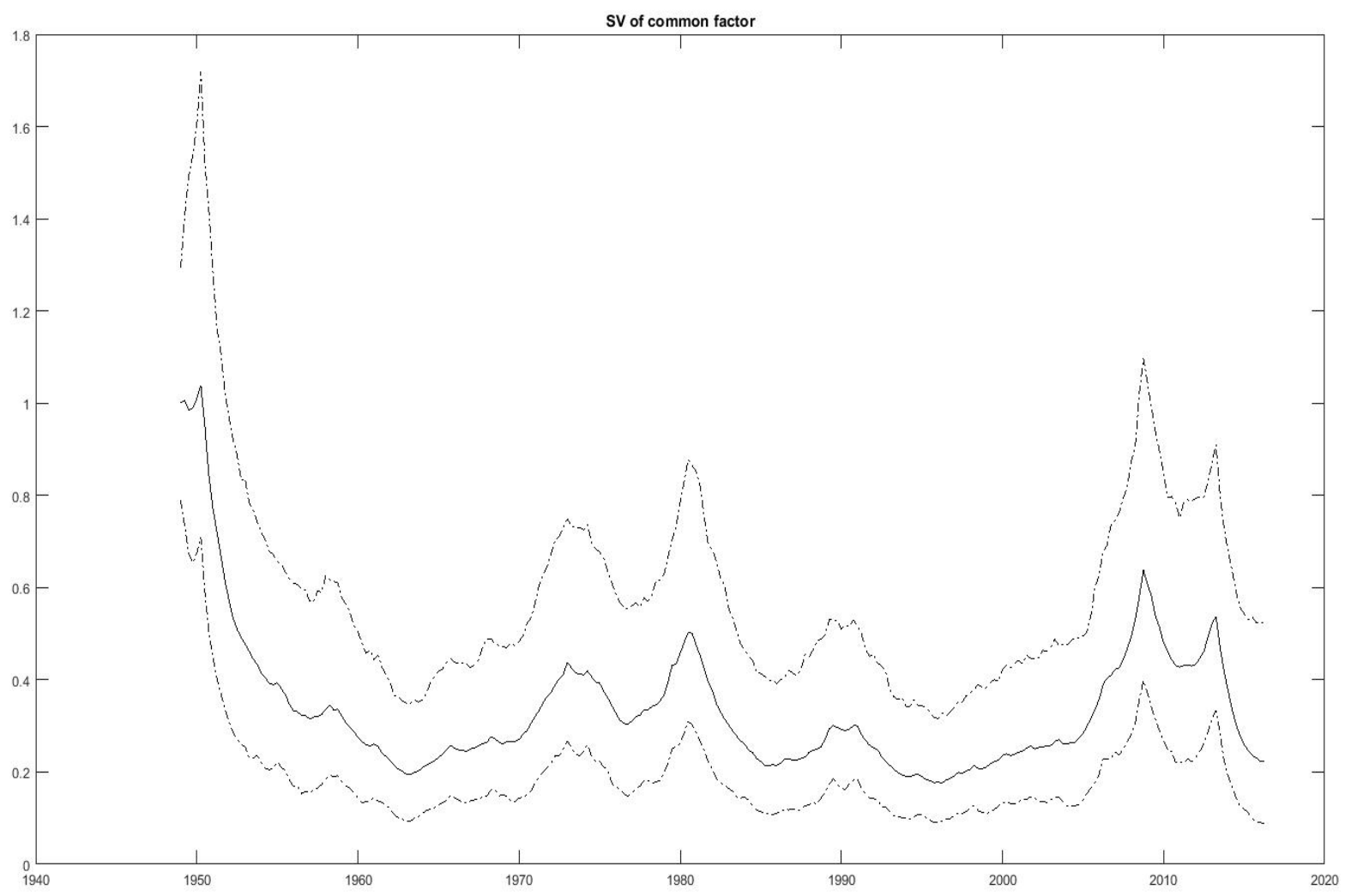


Figure 8. Average Cross-Correlation of Real Personal Income Growth in 48 States

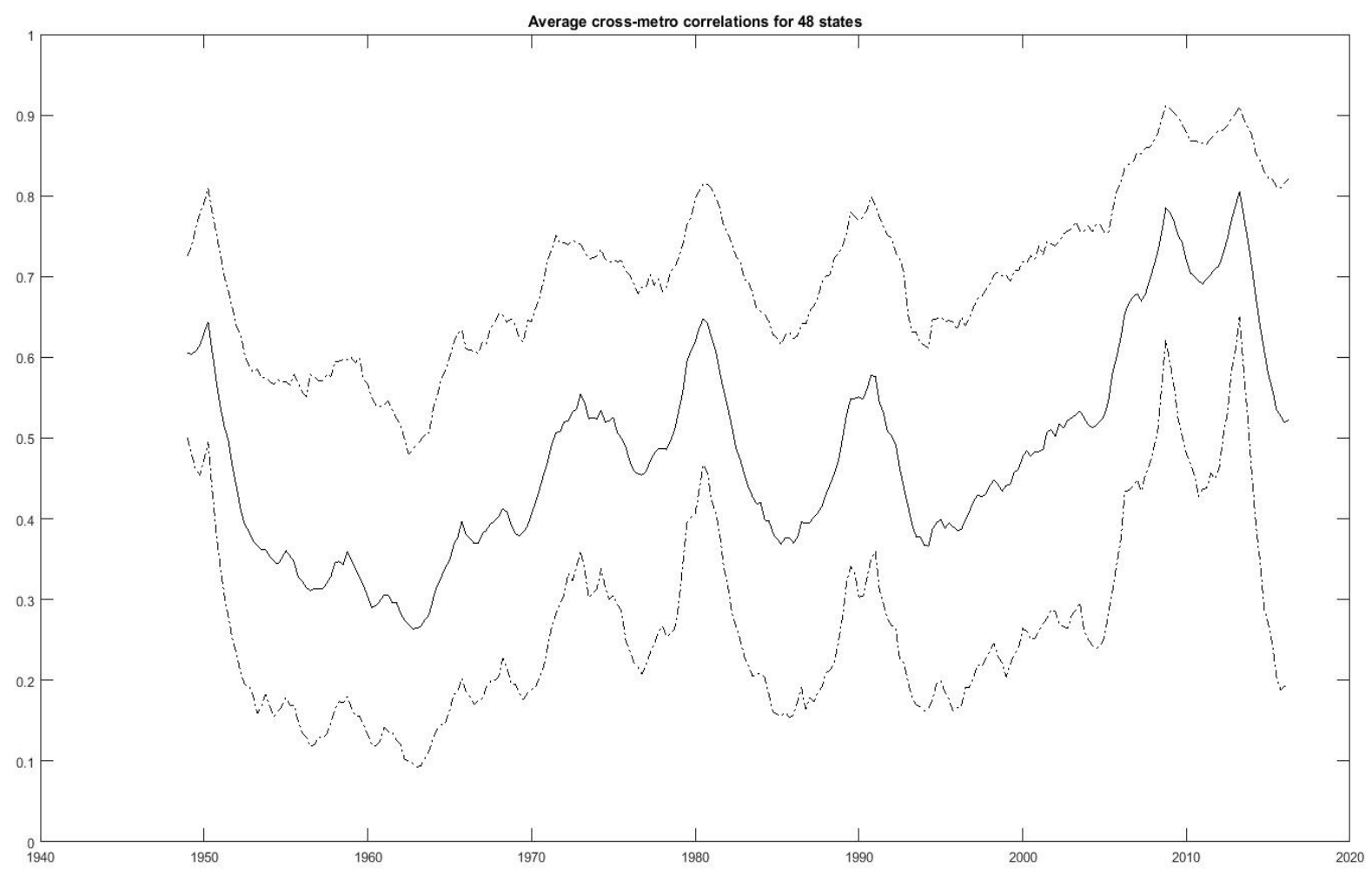

Figure 9. $t$-statistics of the Impact of Uncertainty on the National Factor of the Economic Activity Indices of the MSAs 


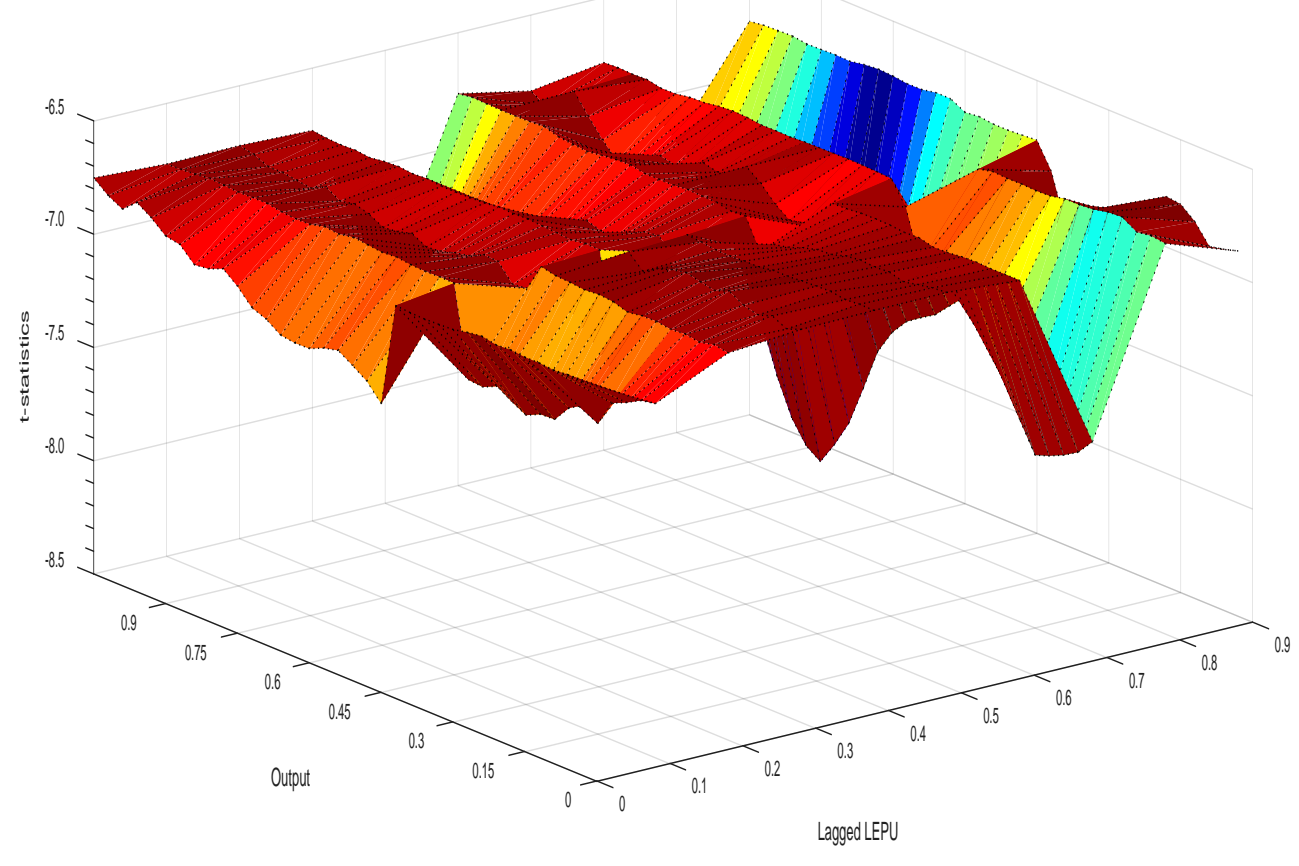

Figure 10. $t$-statistics of the Impact of Uncertainty on the National Factor of the Stochastic Volatility of the MSAs

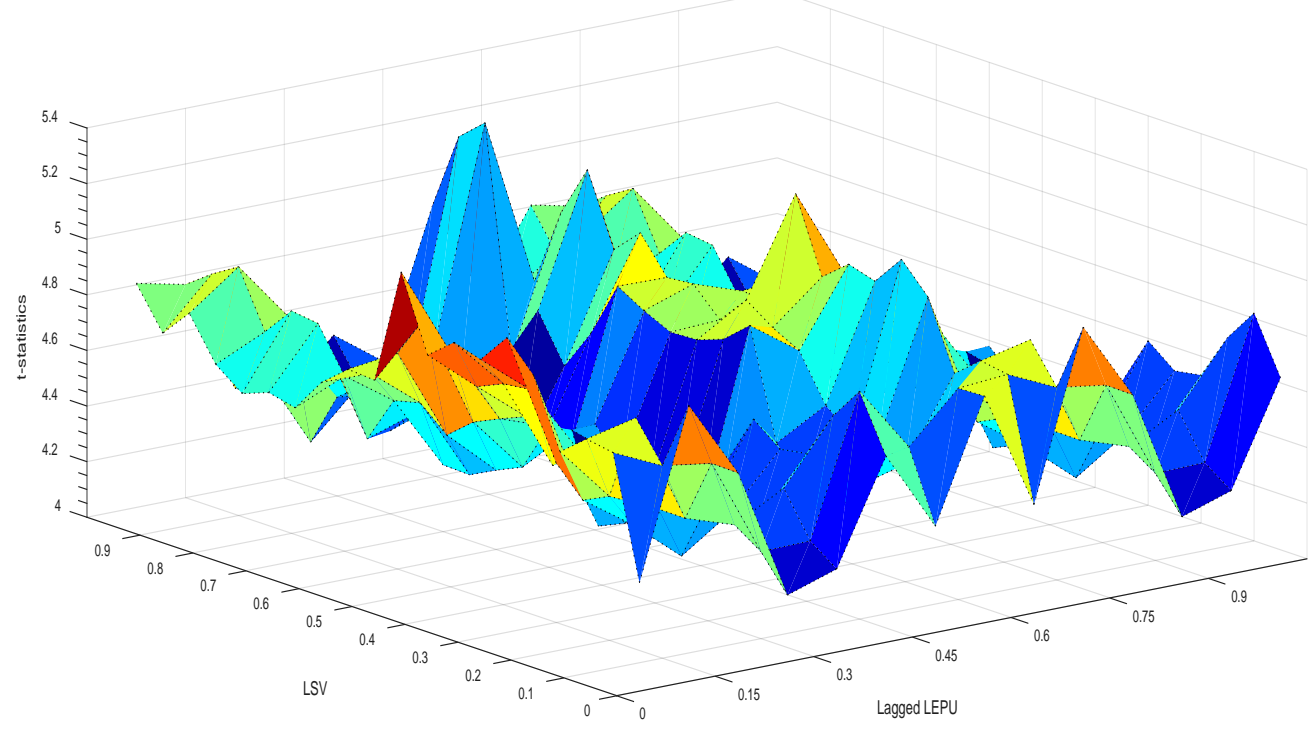

Figure 11. $t$-statistics of the Impact of Uncertainty on the National Factor of Growth of Real Personal Income Growth of the States 


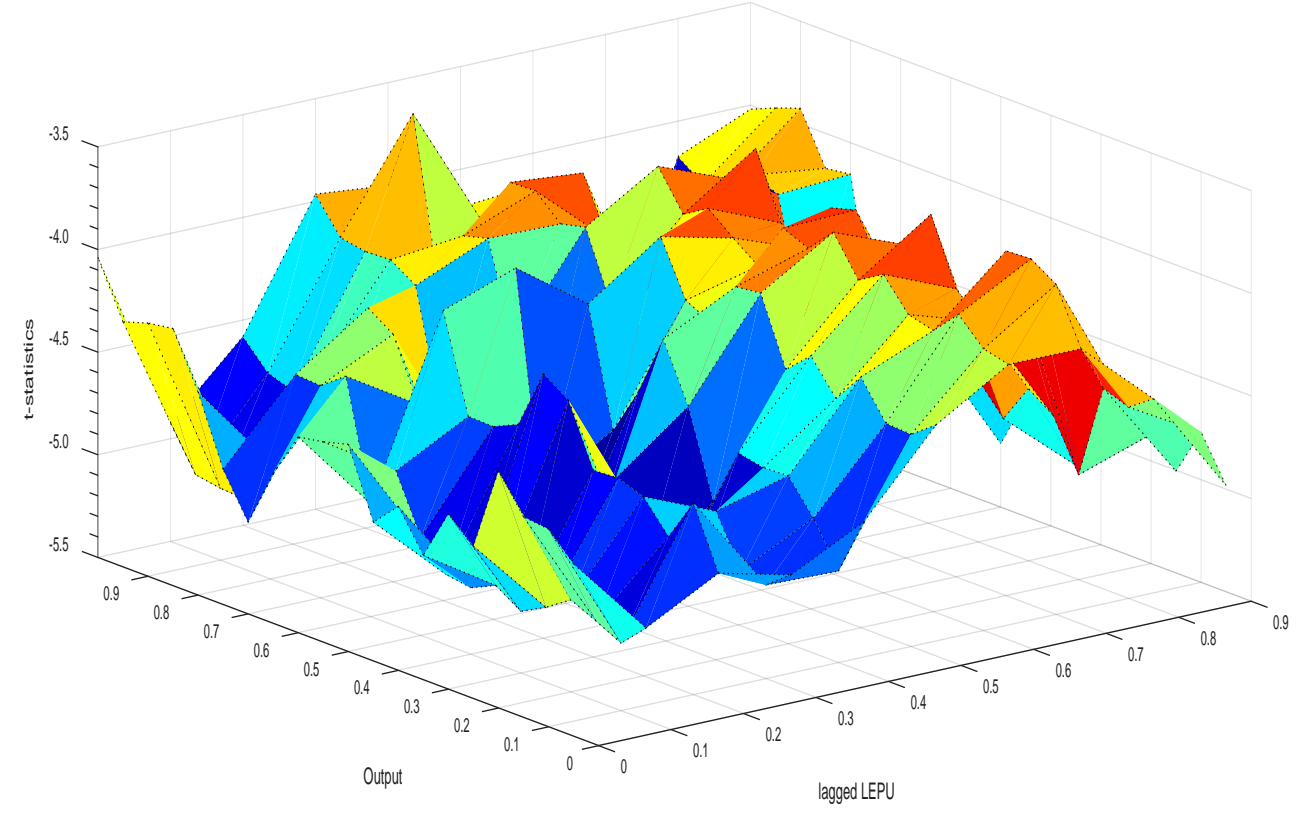


Figure 12. $t$-statistics of the Impact of Uncertainty on the National Factor of Stochastic Volatility of Real Personal Income Growth of the States

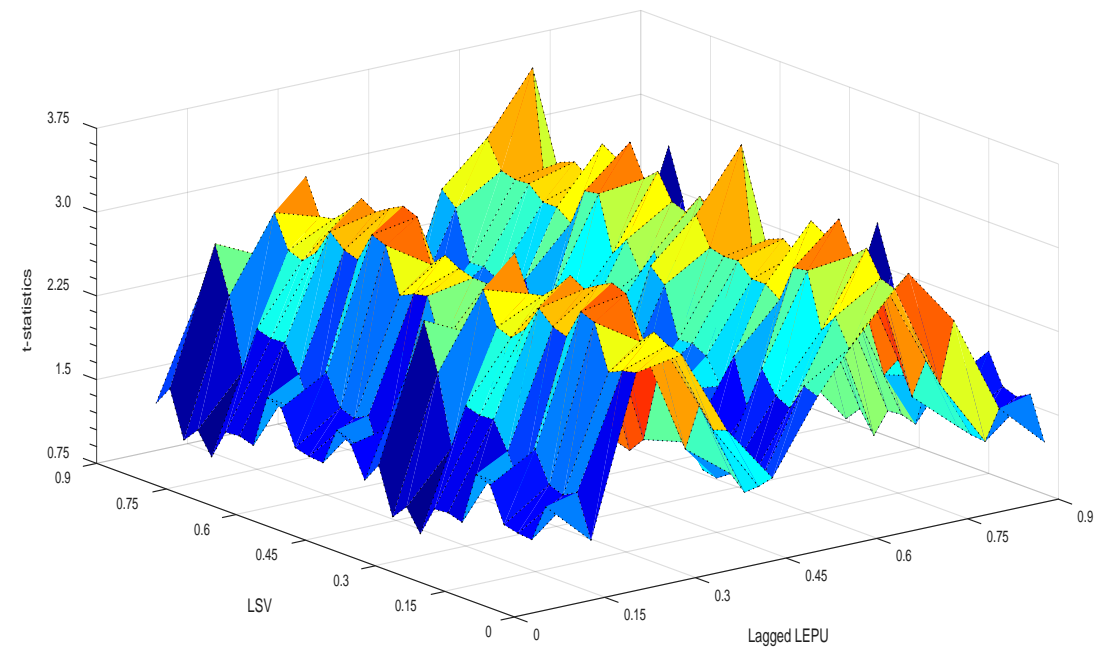


APPENDIX:

Table A1. List of MSAs:

\begin{tabular}{|c|c|}
\hline MSA Symbol & MSA Name \\
\hline STLAGRIDX & St. Louis \\
\hline STWAGRIDX & Seattle-Tacoma-Bellevue \\
\hline LASAGRIDX & Los Angeles-Long Beach-Santa Ana \\
\hline NVLAGRIDX & $\begin{array}{l}\text { Nashville-Davidson--Murfreesboro-- } \\
\text { Franklin }\end{array}$ \\
\hline DFWAGRIDX & Dallas-Fort Worth-Arlington \\
\hline HNBAGRIDX & Hartford-West Hartford-East Hartford \\
\hline BSLAGRIDX & Boston-Cambridge-Quincy \\
\hline DWLAGRIDX & Detroit-Warren-Dearborn \\
\hline MIMAGRIDX & Miami-Fort Lauderdale-West Palm Beach \\
\hline PHXAGRIDX & Phoenix-Mesa-Scottsdale \\
\hline SFCAGRIDX & San Francisco-Oakland-Hayward \\
\hline ATLAGRIDX & Atlanta-Sandy Springs-Marietta \\
\hline KNCAGRIDX & Kansas City \\
\hline NORAGRIDX & New Orleans-Metairie \\
\hline NYLAGRIDX & New York-Newark-Jersey City \\
\hline TMAAGRIDX & Tampa-St. Petersburg-Clearwater \\
\hline BIRAGRIDX & Birmingham-Hoover \\
\hline BUFAGRIDX & Buffalo-Cheektowaga-Niagara Falls \\
\hline CVLAGRIDX & Cleveland-Elyria \\
\hline DNVAGRIDX & Denver-Aurora-Lakewood \\
\hline HTNAGRIDX & Houston-The Woodlands-Sugar Land \\
\hline INDAGRIDX & Indianapolis-Carmel-Anderson \\
\hline LOIAGRIDX & Louisville/Jefferson County \\
\hline MSPAGRIDX & Minneapolis-St. Paul-Bloomington \\
\hline ORLAGRIDX & Orlando-Kissimmee-Sanford \\
\hline PCWAGRIDX & Philadelphia-Camden-Wilmington \\
\hline PORAGRIDX & Portland-Vancouver-Hillsboro \\
\hline WAAAGRIDX & Washington-Arlington-Alexandria \\
\hline AUSAGRIDX & Austin-Round Rock \\
\hline CGRAGRIDX & Charlotte-Concord-Gastonia \\
\hline CHIAGRIDX & Chicago-Naperville-Joliet \\
\hline CTIAGRIDX & Cincinnati-Middletown \\
\hline JAXAGRIDX & Jacksonville \\
\hline LSVAGRIDX & Las Vegas-Henderson-Paradise \\
\hline MWKAGRIDX & Milwaukee-Waukesha-West Allis \\
\hline OKCAGRIDX & Oklahoma City \\
\hline RCPAGRIDX & Richmond \\
\hline SDIAGRIDX & San Diego-Carlsbad \\
\hline SSCAGRIDX & San Jose-Sunnyvale-Santa Clara \\
\hline SYOAGRIDX & Sacramento--Roseville--Arden-Arcade \\
\hline
\end{tabular}




\begin{tabular}{|c|c|} 
BTMAGRIDX & Baltimore-Towson \\
\hline COLAGRIDX & Columbus \\
\hline LRSAGRIDX & Little Rock-North Little Rock-Conway \\
\hline NFKAGRIDX & Virginia Beach-Norfolk-Newport News \\
\hline PITAGRIDX & Pittsburgh \\
\hline PPWAGRIDX & Providence-Warwick \\
\hline RCYAGRIDX & Raleigh \\
\hline RSBAGRIDX & Riverside-San Bernardino-Ontario \\
\hline SATAGRIDX & San Antonio-New Braunfels \\
\hline SLCAGRIDX & Salt Lake City \\
\hline MPHAGRIDX & Memphis \\
\hline
\end{tabular}


Table A.2. Percentage Contribution of the National Factor to Real Personal Income of US States

\begin{tabular}{|c|c|c|c|}
\hline & $\begin{array}{l}\text { Full Sample } \\
\text { Average }\end{array}$ & $\begin{array}{r}\text { Average } \\
\text { before } \\
2007 Q 4\end{array}$ & $\begin{array}{r}\text { Average after } \\
2007 Q 4\end{array}$ \\
\hline Alabama & $68.11 \%$ & $66.69 \%$ & $78.08 \%$ \\
\hline Arizona & $46.62 \%$ & $41.57 \%$ & $81.95 \%$ \\
\hline Arkansas & $46.46 \%$ & $42.37 \%$ & $75.13 \%$ \\
\hline California & $60.67 \%$ & $59.14 \%$ & $71.38 \%$ \\
\hline Colorado & $54.04 \%$ & $49.94 \%$ & $82.71 \%$ \\
\hline Connecticut & $56.78 \%$ & $52.73 \%$ & $85.15 \%$ \\
\hline Delaware & $39.22 \%$ & $35.48 \%$ & $65.38 \%$ \\
\hline Florida & $50.94 \%$ & $47.60 \%$ & $74.30 \%$ \\
\hline Georgia & $72.33 \%$ & $70.93 \%$ & $82.11 \%$ \\
\hline Idaho & $39.28 \%$ & $33.76 \%$ & $77.89 \%$ \\
\hline Illinois & $69.91 \%$ & $67.77 \%$ & $84.94 \%$ \\
\hline Indiana & $65.92 \%$ & $64.87 \%$ & $73.29 \%$ \\
\hline Iowa & $29.26 \%$ & $26.53 \%$ & $48.38 \%$ \\
\hline Kansas & $44.32 \%$ & $41.29 \%$ & $65.51 \%$ \\
\hline Kentucky & $64.59 \%$ & $62.00 \%$ & $82.71 \%$ \\
\hline Louisiana & $39.98 \%$ & $36.58 \%$ & $63.80 \%$ \\
\hline Maine & $41.63 \%$ & $38.28 \%$ & $65.04 \%$ \\
\hline Maryland & $56.16 \%$ & $53.10 \%$ & $77.58 \%$ \\
\hline Massachusetts & $56.93 \%$ & $54.22 \%$ & $75.88 \%$ \\
\hline Michigan & $53.29 \%$ & $49.98 \%$ & $76.47 \%$ \\
\hline Minnesota & $51.60 \%$ & $48.54 \%$ & $73.04 \%$ \\
\hline Mississippi & $44.70 \%$ & $42.79 \%$ & $58.09 \%$ \\
\hline Missouri & $71.96 \%$ & $69.80 \%$ & $87.08 \%$ \\
\hline Montana & $29.34 \%$ & $23.42 \%$ & $70.78 \%$ \\
\hline Nebraska & $23.24 \%$ & $21.18 \%$ & $37.66 \%$ \\
\hline Nevada & $37.70 \%$ & $33.17 \%$ & $69.46 \%$ \\
\hline New Hampshire & $49.63 \%$ & $46.43 \%$ & $72.03 \%$ \\
\hline New Jersey & $60.66 \%$ & $57.40 \%$ & $83.45 \%$ \\
\hline New Mexico & $45.92 \%$ & $41.74 \%$ & $75.21 \%$ \\
\hline New York & $43.27 \%$ & $40.85 \%$ & $60.22 \%$ \\
\hline North Carolina & $62.60 \%$ & $59.75 \%$ & $82.56 \%$ \\
\hline North Dakota & $12.34 \%$ & $10.20 \%$ & $27.37 \%$ \\
\hline Ohio & $71.09 \%$ & $69.40 \%$ & $82.90 \%$ \\
\hline Oklahoma & $48.60 \%$ & $45.72 \%$ & $68.77 \%$ \\
\hline Oregon & $58.89 \%$ & $56.76 \%$ & $73.80 \%$ \\
\hline Pennsylvania & $69.45 \%$ & $67.20 \%$ & $85.20 \%$ \\
\hline Rhode Island & $42.25 \%$ & $39.36 \%$ & $62.51 \%$ \\
\hline South Carolina & $62.12 \%$ & $58.66 \%$ & $86.31 \%$ \\
\hline South Dakota & $16.54 \%$ & $14.74 \%$ & $29.19 \%$ \\
\hline Tennessee & $69.89 \%$ & $67.76 \%$ & $84.75 \%$ \\
\hline Texas & $55.23 \%$ & $52.67 \%$ & $73.10 \%$ \\
\hline Utah & $52.63 \%$ & $49.30 \%$ & $75.94 \%$ \\
\hline
\end{tabular}




\begin{tabular}{|llll|}
\hline Vermont & $56.63 \%$ & $54.57 \%$ & $71.01 \%$ \\
Virginia & $60.62 \%$ & $56.58 \%$ & $88.88 \%$ \\
Washington & $49.75 \%$ & $45.44 \%$ & $79.88 \%$ \\
West Virginia & $42.52 \%$ & $38.25 \%$ & $72.44 \%$ \\
Wisconsin & $73.63 \%$ & $72.20 \%$ & $83.67 \%$ \\
Wyoming & $27.31 \%$ & $24.93 \%$ & $43.95 \%$ \\
\hline AVERAGE & $50.97 \%$ & $47.99 \%$ & $71.81 \%$ \\
\hline
\end{tabular}


Table A.3. Percentage Contribution of the National Factor to Real Personal Income of US MSAs

\begin{tabular}{|c|c|c|c|}
\hline & $\begin{array}{l}\text { Full Sample } \\
\text { Average }\end{array}$ & $\begin{array}{r}\text { Average before } \\
2007 \mathrm{Q} 4\end{array}$ & $\begin{array}{r}\text { Average after } \\
2007 Q 4\end{array}$ \\
\hline STLAGRIDX & $21.83 \%$ & $17.89 \%$ & $30.27 \%$ \\
\hline STWAGRIDX & $20.51 \%$ & $17.85 \%$ & $26.21 \%$ \\
\hline LASAGRIDX & $18.95 \%$ & $16.23 \%$ & $24.79 \%$ \\
\hline NVLAGRIDX & $34.52 \%$ & $29.33 \%$ & $45.64 \%$ \\
\hline DFWAGRIDX & $35.67 \%$ & $31.21 \%$ & $45.23 \%$ \\
\hline HNBAGRIDX & $22.55 \%$ & $16.74 \%$ & $34.98 \%$ \\
\hline BSLAGRIDX & $30.29 \%$ & $29.21 \%$ & $32.60 \%$ \\
\hline DWLAGRIDX & $43.20 \%$ & $35.88 \%$ & $58.88 \%$ \\
\hline MIMAGRIDX & $63.02 \%$ & $56.16 \%$ & $77.70 \%$ \\
\hline PHXAGRIDX & $20.16 \%$ & $16.44 \%$ & $28.12 \%$ \\
\hline SFCAGRIDX & $29.23 \%$ & $28.24 \%$ & $31.33 \%$ \\
\hline ATLAGRIDX & $10.08 \%$ & $8.09 \%$ & $14.34 \%$ \\
\hline KNCAGRIDX & $46.18 \%$ & $43.29 \%$ & $52.37 \%$ \\
\hline NORAGRIDX & $9.34 \%$ & $11.19 \%$ & $5.38 \%$ \\
\hline NYLAGRIDX & $69.60 \%$ & $65.56 \%$ & $78.23 \%$ \\
\hline TMAAGRIDX & $8.05 \%$ & $5.51 \%$ & $13.50 \%$ \\
\hline BIRAGRIDX & $64.03 \%$ & $62.52 \%$ & $67.27 \%$ \\
\hline BUFAGRIDX & $26.40 \%$ & $21.97 \%$ & $35.89 \%$ \\
\hline CVLAGRIDX & $45.37 \%$ & $40.77 \%$ & $55.24 \%$ \\
\hline DNVAGRIDX & $55.22 \%$ & $53.41 \%$ & $59.10 \%$ \\
\hline HTNAGRIDX & $15.30 \%$ & $13.16 \%$ & $19.89 \%$ \\
\hline INDAGRIDX & $39.85 \%$ & $32.53 \%$ & $55.54 \%$ \\
\hline LOIAGRIDX & $41.36 \%$ & $37.81 \%$ & $48.96 \%$ \\
\hline MSPAGRIDX & $76.81 \%$ & $75.94 \%$ & $78.66 \%$ \\
\hline ORLAGRIDX & $14.33 \%$ & $11.77 \%$ & $19.83 \%$ \\
\hline PCWAGRIDX & $72.31 \%$ & $70.35 \%$ & $76.53 \%$ \\
\hline PORAGRIDX & $66.17 \%$ & $65.74 \%$ & $67.10 \%$ \\
\hline WAAAGRIDX & $31.59 \%$ & $27.83 \%$ & $39.65 \%$ \\
\hline AUSAGRIDX & $13.51 \%$ & $11.84 \%$ & $17.08 \%$ \\
\hline CGRAGRIDX & $74.00 \%$ & $67.42 \%$ & $88.10 \%$ \\
\hline CHIAGRIDX & $81.00 \%$ & $78.43 \%$ & $86.51 \%$ \\
\hline CTIAGRIDX & $49.16 \%$ & $41.98 \%$ & $64.54 \%$ \\
\hline JAXAGRIDX & $6.17 \%$ & $3.14 \%$ & $12.66 \%$ \\
\hline LSVAGRIDX & $28.81 \%$ & $25.51 \%$ & $35.88 \%$ \\
\hline MWKAGRIDX & $51.04 \%$ & $47.48 \%$ & $58.68 \%$ \\
\hline OKCAGRIDX & $25.24 \%$ & $17.44 \%$ & $41.93 \%$ \\
\hline RCPAGRIDX & $66.48 \%$ & $62.83 \%$ & $74.30 \%$ \\
\hline SDIAGRIDX & $6.61 \%$ & $4.61 \%$ & $10.89 \%$ \\
\hline SSCAGRIDX & $22.49 \%$ & $15.65 \%$ & $37.14 \%$ \\
\hline SYOAGRIDX & $2.70 \%$ & $1.62 \%$ & $5.00 \%$ \\
\hline BTMAGRIDX & $42.11 \%$ & $40.73 \%$ & $45.04 \%$ \\
\hline COLAGRIDX & $26.01 \%$ & $21.05 \%$ & $36.62 \%$ \\
\hline
\end{tabular}




\begin{tabular}{|lcrr|} 
LRSAGRIDX & $36.71 \%$ & $37.98 \%$ & $33.99 \%$ \\
NFKAGRIDX & $48.48 \%$ & $42.35 \%$ & $61.62 \%$ \\
PITAGRIDX & $24.56 \%$ & $21.74 \%$ & $30.61 \%$ \\
PPWAGRIDX & $16.96 \%$ & $16.05 \%$ & $18.92 \%$ \\
RCYAGRIDX & $25.37 \%$ & $19.58 \%$ & $37.77 \%$ \\
RSBAGRIDX & $4.23 \%$ & $3.28 \%$ & $6.29 \%$ \\
SATAGRIDX & $13.33 \%$ & $9.17 \%$ & $22.26 \%$ \\
SLCAGRIDX & $15.58 \%$ & $12.94 \%$ & $21.23 \%$ \\
MPHAGRIDX & $11.21 \%$ & $8.85 \%$ & $16.27 \%$ \\
\hline AVERAGE & $33.80 \%$ & $30.48 \%$ & $40.91 \%$ \\
\hline
\end{tabular}

Figure A1. t-statistics from Quantile Regressions

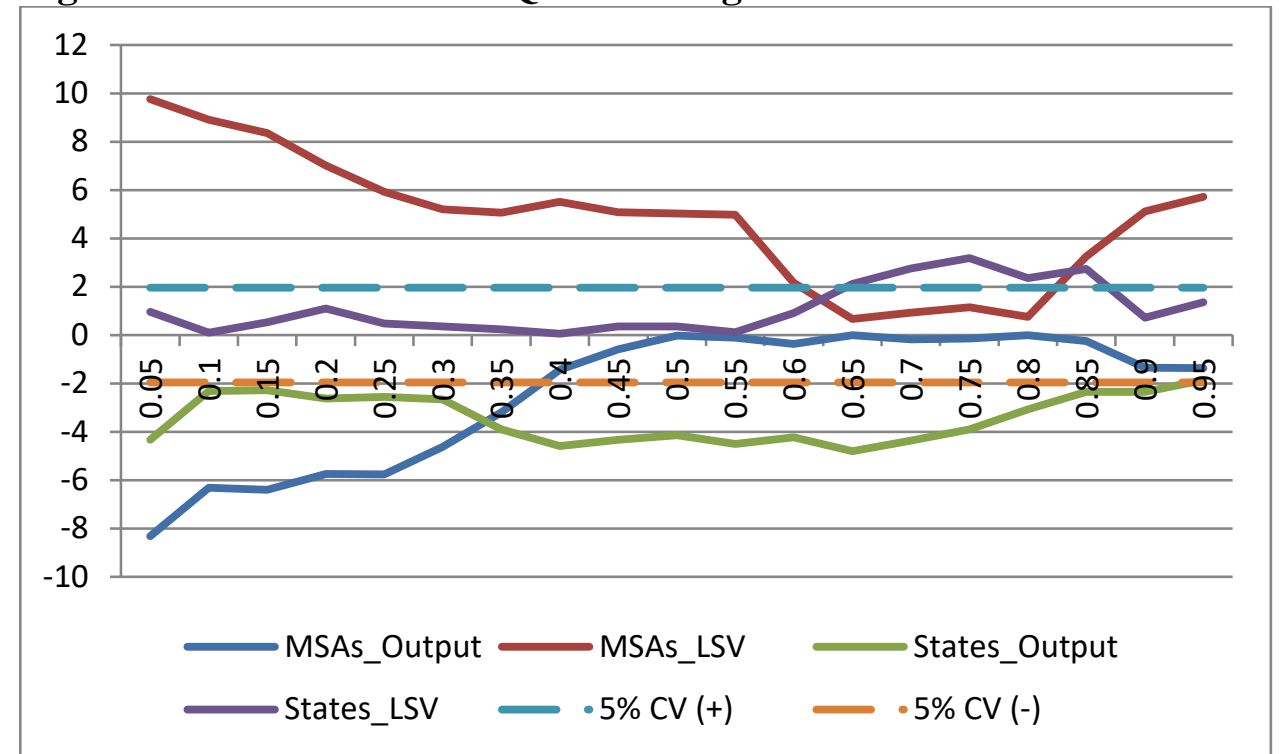

Notes: MSAs_Ouput (States_Output) and MSAs_LSV (States_LSV) are the National Factor of the Economic Activity Indices of the MSAs (National Factor of Growth of Real Personal Income Growth of the States), and National Factor of Stochastic Volatility of MSAs (National Factor of the Stochastic Volatility of Real Personal Income Growth of the States). The Figures correspond to the $t$-statistics of the impact of uncertainty on the MSAs_Ouput, MSAs_LSV, States_Output, and States_LSV. 5\% CV(+) and 5\% CV (-) stands for 1.96 and -1.96 respectively.

Figure A2. Impact of Uncertainty on the National Factor of the Economic Activity Indices of the MSAs 


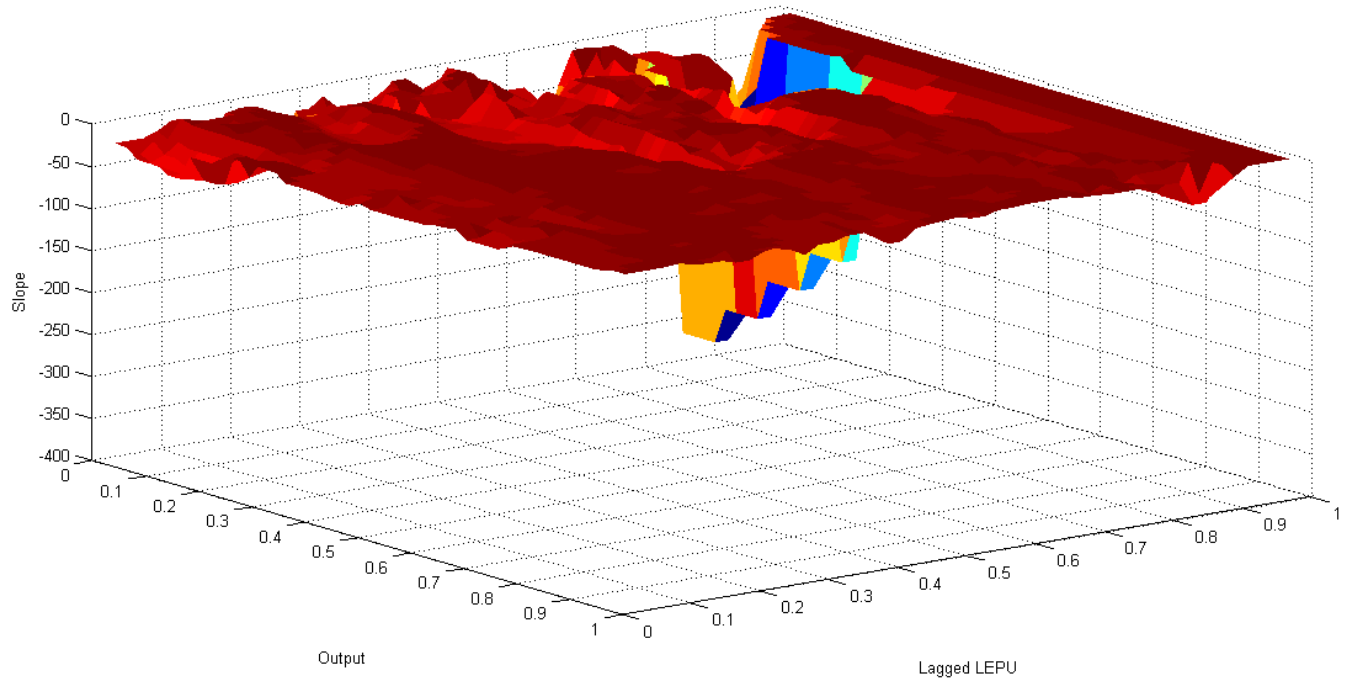

Figure A3. Impact of Uncertainty on the National Factor of the Stochastic Volatility of the MSAs

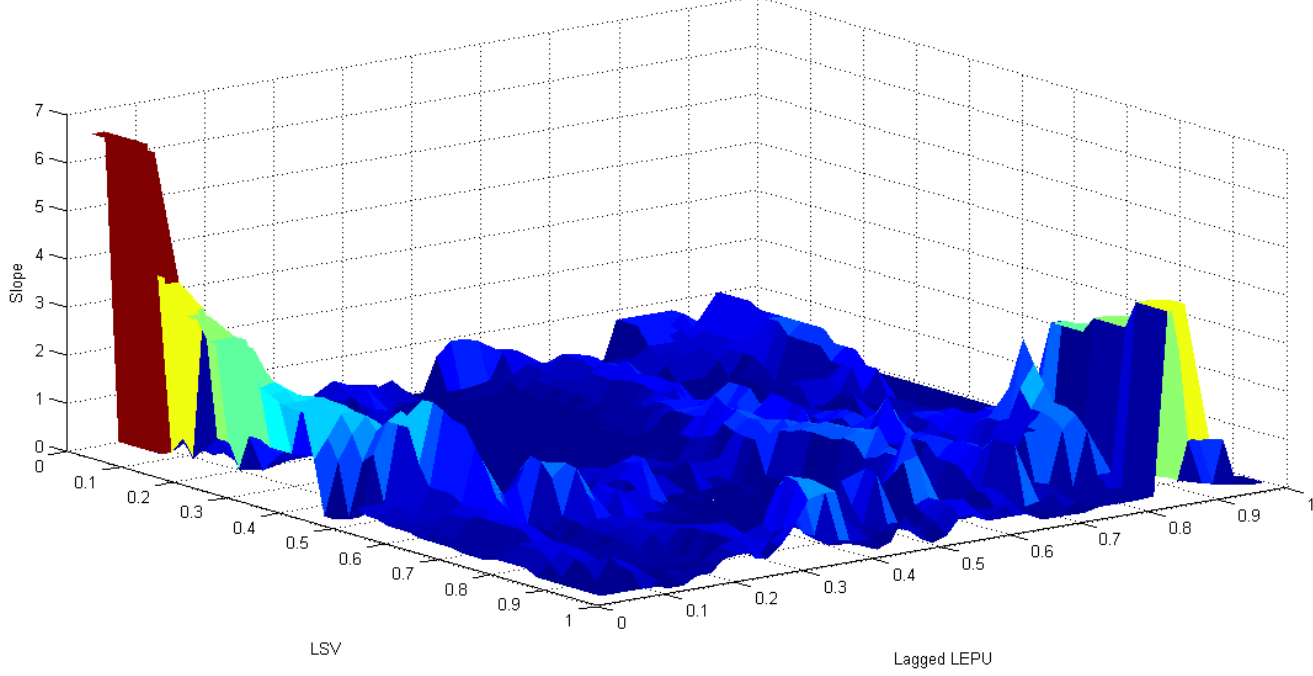

Figure A4. Impact of Uncertainty on the National Factor of Growth of Real Personal Income Growth of the States 


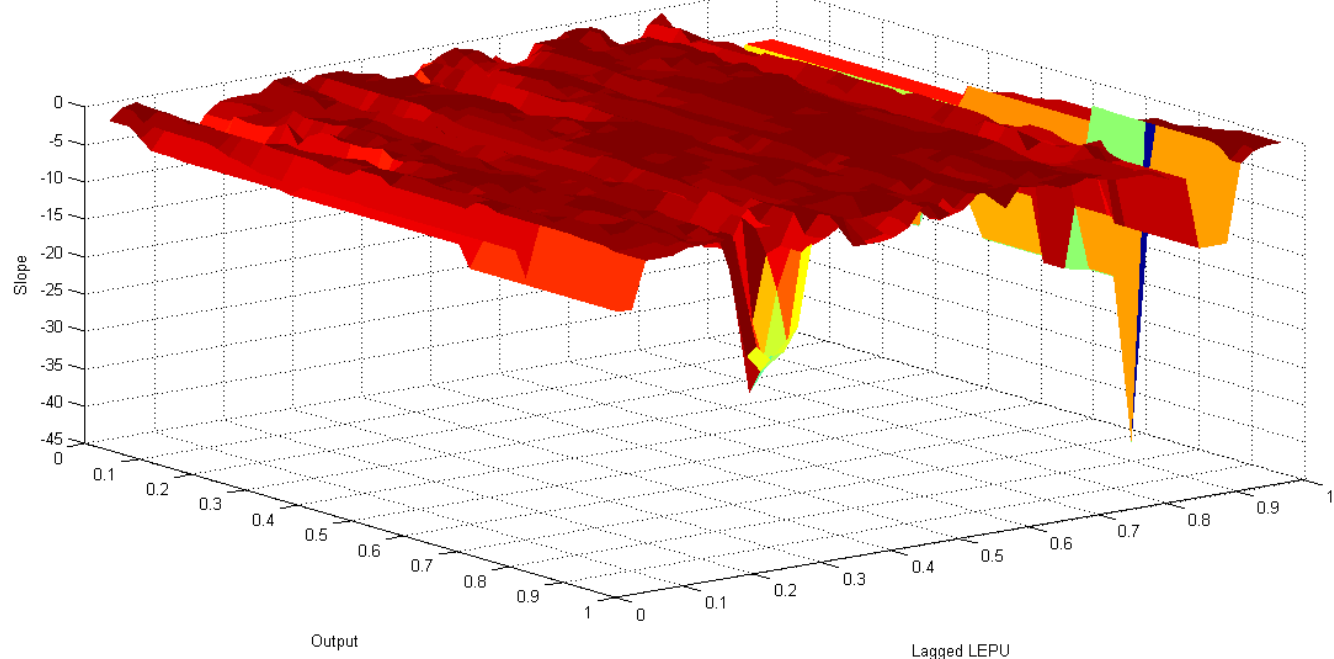

Figure A5. Impact of Uncertainty on the National Factor of Stochastic Volatility of Real Personal Income Growth of the States

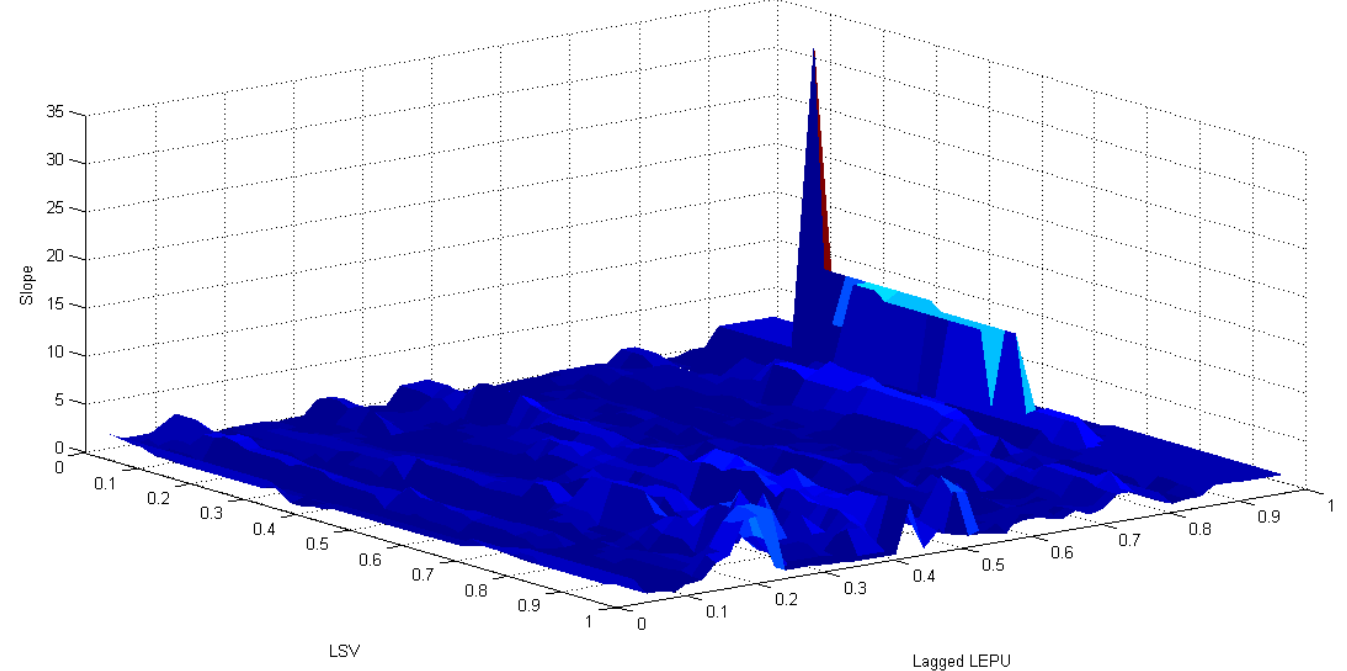

